Jurnal International Bereputasi

Scopus Q4

Ahmad Ni'matullah Al-Baarri

Sebagai Corresponding Author

(Bukti terlampir)

International Journal of Dairy Science 9 (2): 56-62, 2014

ISSN 1811-9743 / DOI: 10.3923/ijds.2014.56.62

(C) 2014 Academic Journals Inc.

\title{
Resistance of Immobilized Lactoperoxidase Activity from Bovine Whey Against Storage Solutions
}

${ }^{1}$ Dwi Novrina Nawangsari, ${ }^{2}$ Ahmad Ni'matullah Al-Baarri, ${ }^{2}$ Sri Mulyani, ${ }^{2}$ Anang Mohamad Legowo and ${ }^{2}$ V. Priyo Bintoro

${ }^{1}$ Department of Animal Product Technology,

${ }^{2}$ Department of Food Technology, Faculty of Animal and Agricultural Sciences, Diponegoro University, Semarang, Indonesia

Corresponding Author: Ahmad Ni'matullah Al-Baari, Department of food Technology, Faculty of Animal and Agricultural Sciences, Diponegoro University, Semarang, Indonesia 
International Journal of Dairy Science 9 (2): 56-62, 2014

ISSN 1811-9743 / DOI: 10.3923/ijds.2014.56.62

(C) 2014 Academic Journals Inc.

\title{
Resistance of Immobilized Lactoperoxidase Activity from Bovine Whey Against Storage Solutions
}

\author{
${ }^{1}$ Dwi Novrina Nawangsari, ${ }^{2}$ Ahmad Ni'matullah Al-Baarri, ${ }^{2}$ Sri Mulyani, \\ ${ }^{2}$ Anang Mohamad Legowo and ${ }^{2}$ V. Priyo Bintoro \\ ${ }^{1}$ Department of Animal Product Technology, \\ ${ }^{2}$ Department of Food Technology, Faculty of Animal and Agricultural Sciences, Diponegoro University, \\ Semarang, Indonesia
}

Corresponding Author: Ahmad Ni'matullah Al-Baari, Department of food Technology, Faculty of Animal and Agricultural Sciences, Diponegoro University, Semarang, Indonesia

\begin{abstract}
Lactoperoxidase (LPO) could be simply obtained from whey through immobilization using a cation exchange resin of SP Sepharose. LPO received high attention since the antimicrobial properties of LPO system (LPOS) that are consisted of $\mathrm{LPO}, \mathrm{SCN}^{-}$and $\mathrm{H}_{2} \mathrm{O}_{2}$ was able to generate $\mathrm{OSCN}^{-}$for strong antimicrobial agents. This study was done to analyze the immobilization efficiency of LPO onto two types of sepharose: SP-Sepharose Fast Flow (SPFF) and SP-Sepharose Big Beads (SPBB). The remaining of LPO's activity (\%) against storage solution was also observed. The whey was obtained from bovine skimmed milk that was coagulated using rennet and acid lactic. The LPO was obtained from whey using SPFF. To analyze the resistence of enzyme activity, the immobilized LPO was stored in pure water, phosphate buffer, milk and whey at $10^{\circ} \mathrm{C}$. The activity of LPO was monitored for 10 days. The result indicates that the LPO could be purified from whey and single band has been detected using electrophoresis method. The obtained LPO (35 $\mathrm{U} \mathrm{mL}^{-1}$ ) was attached onto SPFF and SPBB. Maximum immobilization efficiency has been achieved by $0.6 \mathrm{~g}$ SP-FF and $0.9 \mathrm{~g}$ SP-BB. LPO activity of the immobilized LPO were able to be kept until 5 days when it was stored in whey. Other storage solution remained various LPO activity during storage. This study concluded that IE of LPO attached onto sepharoses might be reached variously depended on the sepharose type and whey as LPO source might be used for maintaining LPO activity.
\end{abstract}

Key words: Lactoperoxidase, SP sepharose fast flow, SP sepharose big beads, immobilization, remaining activity

\section{INTRODUCTION}

Lactoperoxidase (LPO), together with $\mathrm{SCN}^{-}$and $\mathrm{H}_{2} \mathrm{O}_{2}$ have been understood to generates intermediate product of $\mathrm{OSCN}^{-}$as antibacterial agent that has a broad spectrum of antimicrobial effects against bacteria, fungi and viruses. This antibacterial agent could be produced if these three components exist in the medium (Seifu et $a l ., 2005$ ). LPOS has been widely used as a preservative in dairy products and nondairy products (Seifu et al., 2004; Touch et al., 2004; FAO/WHO, 2005; Boots and Floris, 2006; Oghaiki et al., 2007; Fweja et al., 2008; Al-Baarri et al., 2011a).

It has been understood that whey contains large number of LPO therefore purification method of LPO from whey has been well developed (Touch et al., 2004; Zhou and Lim, 2009; 
Al-Baarri et al., 2010). SP-Sepharose has been known to provide beneficial effect for the immobilization efficiency since SP-Sepharose almost completely immobilized LPO and reusable (Al-Baarri et al., 2010). Although, LPOS was widely used in food application but it still remained the problem of its expensiveness, therefore the immobilization of LPO was needed for the reuse of LPO.

SP Sepharose has been known as immobilization agent for capturing lactoperoxidase (Fee and Chand, 2006; Hayashi et al., 2012). SP Sepharose Fast Flow (SPFF) and SP Sepharose Big Beads (SPBB) were the common resin for immobilization since the they provide simply application, long term of use and easy for reuse (Amersham-Bioscience, 2001). If compare to other immobilization agent such as chitosan, SP Sepharoses showed higher capturization of lactoperoxidase (Al-Baarri et al., 2012). In the other hand, SP Sepharose application for immobilization of LPO resulting in the much more expensive of the use of LPO, therefore the efficient use of SP Sepharose to immobilize LPO is required. Based on related literatures, there was no documentation for the efficient use of LPO immobilization using SP Sepharose, therefore this research has been done for analyzing the maximum capturization of LPO onto SP Sepharose. This information might provide the benefit for minimum use of SP Sepharose for LPO immobilization. Since the immobilized LPO allowed the reuse of enzyme, the appropriate storage solution for keeping the enzyme activity is needed. To answer this, this research has also been done for analyzing the remaining of LPO activity after storage.

\section{MATERIALS AND METHODS}

Materials: SP Sepharose Fast Flow and SP Sepharose Big Beads were purchased from Amersham Pharmacia Biotech, Sweden (Lot. No. 10029743 and 10081054, respectively). Microbial derived rennet was purchased from Singapore and ABTS or 2,20-azino-bis (3-ethylbenz-thiazoline-6sulphonic acid) was obtained from Kagawa Science (Lot No. 7ROZC-EC) Tokyo Chemical, Industry Co. Ltd., Japan. Cow's milk was obtained from Faculty of Animal and Agricultural Sciences's farm, Diponegoro University, Semarang, Indonesia. The spectrophotometer (Mini UV-1800, Schimadzu, Japan) was used for analysis enzyme activity. Unless other compounds specified, all other compounds were reagent grade.

Preparation of whey: The whey was prepared as method performed by Al-Baarri et al. (2011b) without any modification.

LPO immobilization from whey: The procedure for immobilization of LPO was conducted as the method that was performed by Al-Baarri et al. (2010) with minor modifications. SP Sepharose Fast Flow (SPFF) was used as agent for LPO immobilization from whey. Whey at the volume of $1800 \mathrm{~mL}$ was eluted through a glass column $(3 \times 40 \mathrm{~cm})$ filled with $60 \mathrm{~g}$ of SPFF. Prior to elution, $\mathrm{SPFF}$ was washed with $300 \mathrm{~mL}$ of Phosphate Buffer (PB) (pH 6.8) containing $1 \mathrm{M} \mathrm{NaCl}$ to remove unnecessary compounds. The whey was circulated through the column using feedback tubing and a peristaltic pump. The circulation was done at the flow rate of $1.0 \mathrm{~mL} \mathrm{~min}{ }^{-1}$. After draining the whey away, the resin was washed with $300 \mathrm{~mL}$ of $0.4 \mathrm{mM} \mathrm{NaCl}$ in $0.1 \mathrm{mM}$ phosphate buffer ( $\mathrm{pH}$ 7.0) using fraction collector (10 $\mathrm{mL}$ per tube) to obtain the solution containing high concentration of LPO. Three groups of fractions (fraction number 1-10, 11-20, 21-30) were analyzed for protein profile using sodium dodecyl sulfate polyacrylamide gel electrophoresis 
(SDS-PAGE) to check the purity. Finally, based on the SPS PAGE analysis, the fraction number 21-30 was selected for LPO activity analysis ( $\mathrm{LPO}$ activity was $35 \mathrm{U} \mathrm{mL}^{-1}$ ). Thus, this fraction was used throughout experiment.

Determination of captured LPO onto SP sepharoses: SPFF and SPBB (0.1-1.0 g) were washed in $1 \mathrm{M} \mathrm{NaCl}$ in $\mathrm{PB} \mathrm{pH} 7.0$ and then were placed in the column $(1 \times 10 \mathrm{~cm})$. The immobilization process was started with the elution of $1 \mathrm{~mL}$ of LPO through column. The flow rate was set into $1 \mathrm{~mL} \mathrm{~min}^{-1}$ using peristaltic pump. The output was collected for measurement of remained LPO activity in the SP Sepharoses. This experiment was repeated three times and column were wash with serial elution of $1 \mathrm{M} \mathrm{NaOH}$ and pure water, respectively. The immobilized LPO was stored in pure water, $\mathrm{PB}$, milk and whey. All storage solutions were sterilized using autoclave at $110^{\circ} \mathrm{C}$ for $10 \mathrm{~min}$. Immobilized LPO was stored at $4^{\circ} \mathrm{C}$ for 10 days. The remaining of LPO activity immobilized onto SP-Sepharose was calculated by eluting immobilized LPO using $1 \mathrm{M} \mathrm{NaCl}$ in PB $\mathrm{pH}$ 7.0. The LPO activity in the elution was analyzed spectrometrically.

LPO activity determination: $\mathrm{LPO}$ activity was performed as the following method: $450 \mu \mathrm{L}$ of $1.0 \mathrm{mM}$ ABTS in $10 \mathrm{mM}$ acetate buffer $(\mathrm{pH} 4.4)$ and $450 \mu \mathrm{L}$ of $0.55 \mathrm{mM} \mathrm{H}_{2} \mathrm{O}_{2}$ in pure water were gently poured into the cuvette. The enzyme $(50 \mu \mathrm{L})$ was subsequently added to cuvette. The increase of absorbance at $412 \mathrm{~nm}$ measured for $20 \mathrm{sec}$. One unit of LPO enzymatic activity was expressed as the amount of enzyme needed to oxidize $1 \mu \mathrm{mol}$ ABTS $\mathrm{min}^{-1}$. The molar extinction coefficient of ABTS at $412 \mathrm{~nm}$ was $32.400 \mathrm{M}^{-1} \mathrm{~cm}^{-1}$ (Touch et al., 2004).

Immobilization efficiency: The immobilization efficiency (IE) was calculated as follows:

$$
\operatorname{IE}(\%)=\frac{E_{1}}{E_{0}} \times 100
$$

where, $\mathrm{E}_{0}$ is the LPO activity added to the SP Sepharoses $\left(\mathrm{U} \mathrm{mL}^{-1}\right)$ and $\mathrm{E}_{1}$ is the LPO activity embedded in the SP Sepharose $\left(\mathrm{U} \mathrm{mL}^{-1}\right.$ ) (Al-Baarri et al., 2010).

\section{RESULTS AND DISCUSSION}

Purification LPO: Whey has a lot of enzymes and it is available in low cost because whey is by product of dairy manufacture so it is the challenge to use whey as enzyme sources including LPO. The LPO activity and band(s) of the solution obtained from the elution of $1 \mathrm{M} \mathrm{NaCl}$ in PB pH 7.0 through SPFF containing LPO were checked using spectrophotometer and SDS PAGE, respectively. As mention in methods, SPFF containing LPO was generated from whey that was eluted through $\mathrm{SPFF}$ column. The result of LPO activity was $27.7 \pm 2.9,39.5 \pm 4.5$ and $35.2 \pm 3.4 \mathrm{U} \mathrm{mL}^{-1}$ for fraction number 1-10, 11-20, 21-30, respectively (data not presented). The highest of LPO activity was group of fraction number 11-20, however since the band of this group showed two bands indicating two protein was detected, for whole of experiment, group of fraction number 21-30 was used. This group showed single band indicating only LPO that was captured by SPFF.

In this research SPFF was used to obtain LPO since this ion exchange resin has diameter 45-165 $\mu \mathrm{m}$ resulting in the wider of surface area than SPBB (Amersham-Bioscience, 2001). In line with this result, Touch et al. (2004) used SPFF for purifying LPO from whey resulting in the good 
Int. J. Dairy Sci., 9 (2): 56-62, 2014

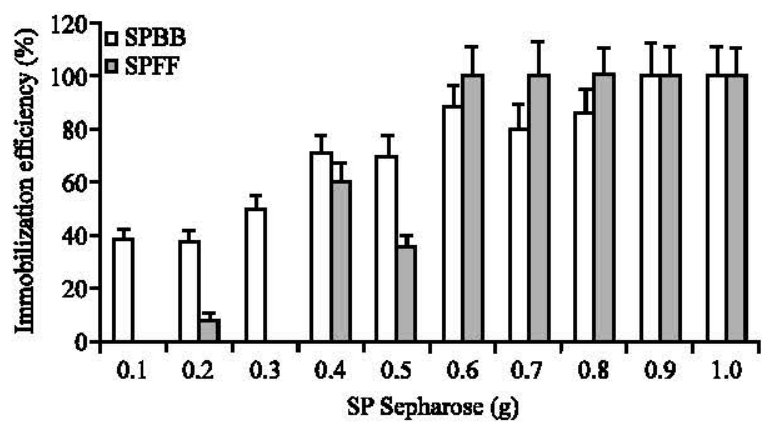

Fig. 1: Immobilization efficiency (IE) of LPO on two types of resin, i.e., SP Sepharose Big Beads (SPBB) and SP Sepharose Fast Flow (SPFF). Two types of resin (0.1-1.0 g) was used to immobilized $1 \mathrm{~mL}$ of LPO (35 $\left.\mathrm{U} \mathrm{mL}^{-1}\right)$. Flow rate has been set to $1 \mathrm{~mL} \mathrm{~min}^{-1}$ using peristaltic pump. Values are means of three sets of experiments, Error bars represent standard errors of the mean

ability to catch LPO (108 $\left.\mathrm{U} \mathrm{mL}^{-1}\right)$. The activity of LPO in this research was less than that of other researcher since the absence of microfiltration step in this research. It has been known that the microfiltration might concentrate the enzyme resulting in the high activity of LPO.

Immobilization efficiency: Immobilization efficiency plays an important role for determination of immobilization agent. This research determined Immobilization Efficiency (IE) of LPO using SPFF dan SPBB (Fig. 1). The volume of SP Sepharoses used in this experiment had a range from 0.1 to $1.0 \mathrm{~g}$ to catch the $\mathrm{LPO}$ at initial activity of $35.2 \pm 3.4 \mathrm{U} \mathrm{mL}^{-1}$. The increase of IE was found as an increase of SP Sepharoses's weight. As describe in Fig. 1, when the $0.6 \mathrm{~g}$ of SPFF was employed, the IE achieved 100\% indicating all of LPO employed was able to be captured by SPFF. When the weight of SPFF was increased, the IE was in steady state maximumly. An increase SPBB from 0.1 to $1.0 \mathrm{~g}$ elevated the IE from 38.6 to $100 \%$. However, $0.9 \mathrm{~g}$ of SPBB completely captured $\mathrm{LPO}$ resulting the IE of $100 \%$. One gram of SPFF was reported to have a maximum capture of LPO in $300 \mathrm{~mL}$ whey (equal to $750 \mathrm{U} \mathrm{mL}^{-1} \mathrm{LPO}$ activity) (Al-Baarri et al., 2010). This can be explained that the capture depended on the quantity of enzymes per mililiter. This research used high activity of LPO resulting in the loss of LPO activity.

Since the SPFF and SPBB provided the maximum IE at 0.6 and $0.9 \mathrm{~g}$, respectively, thus these amounts of SP Sepharoses has been used in the rest of experiment. The LPO immobilized onto SPFF and SPBB was stored in the various storage solutions: Pure water, PB, milk and whey for 10 days at $10^{\circ} \mathrm{C}$.

Remaining LPO activity during storage: The percentage of remaining immobilized LPO activity stored at $10^{\circ} \mathrm{C}$ for 10 days in various storage solutions is shown in Fig. 2a and b. LPO activity of immobilized LPO was measured after purging the LPO attached onto SP Sepharose with $1 \mathrm{M} \mathrm{NaCl}$ in $\mathrm{PB} \mathrm{pH} \mathrm{7.0.} \mathrm{The} \mathrm{percentage} \mathrm{of} \mathrm{remaining} \mathrm{LPO} \mathrm{activity} \mathrm{was} \mathrm{determined} \mathrm{by} \mathrm{comparing}$ the LPO activity after storage to the initial immobilized LPO at first day of storage.

The percentage of LPO activity attached onto SPBB and SPFF is shown on Fig. 2a and b, respectively. Based on Fig. 2a, whey was able to maintain $100 \%$ enzyme activity of LPO attached onto SPBB within 4 days. The extention of storage time resulted in the remarkable 
Int. J. Dairy Sci., 9 (2): 56-62, 2014
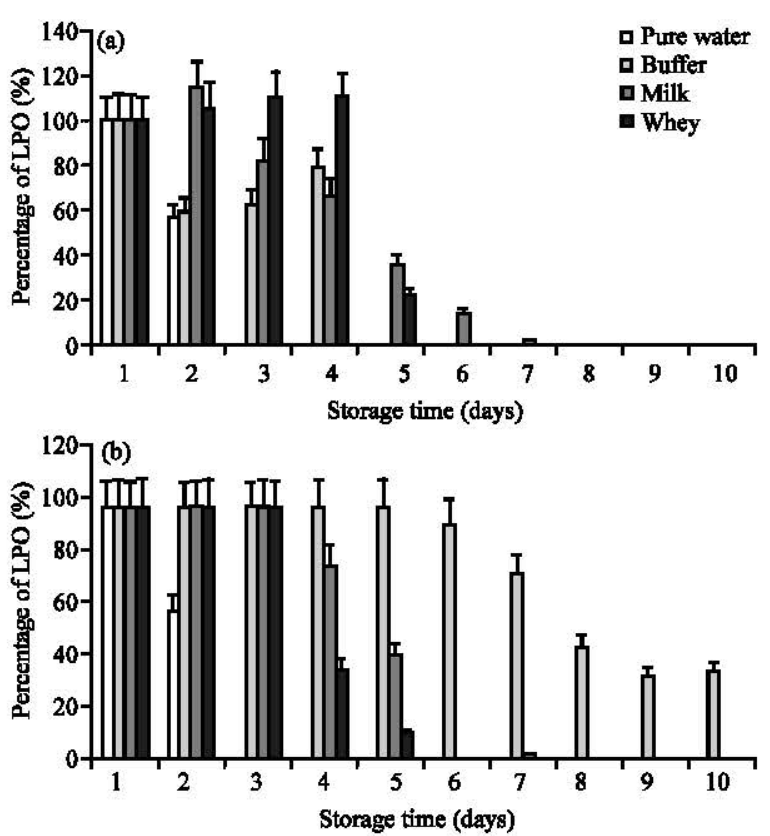

Fig. 2(a-b): (a) Percentage of remaining LPO activity attached onto SP Sepharose Big Beads (SPBB) during 10 days of storage at $10^{\circ} \mathrm{C}$ in various storage solutions. This experiment used $1 \mathrm{~g}$ of SPBB for immobilizing $1 \mathrm{~mL}$ of LPO $\left(35 \mathrm{U} \mathrm{mL}^{-1}\right)$. Immediately after immobilization, SPBB then was stored in sterilized pure water, phosphate buffer, milk and whey for 10 days at $10^{\circ} \mathrm{C}$. Values are mean of three sets of experiments. Error bars represent standard errors of the mean and (b) Percentage of remaining LPO activity attached onto SP Sepharose Fast Flow (SPFF) during 10 days of storage at $10^{\circ} \mathrm{C}$ in various storage solution. This experiment used $1 \mathrm{~g}$ of SPFF for immobilizing $1 \mathrm{~mL}$ of LPO $\left(35 \mathrm{U} \mathrm{mL}^{-1}\right)$. After immobilization, SPFF was stored in sterilized pure water, phosphate buffer, milk and whey. Values are mean of three sets of experiments. Error bars represent standard errors of the mean

reduction of remaining $\mathrm{LPO}$ activity. Milk was able to maintain the LPO activity at seven days of storage even though the remaining of LPO activity at that time was very negligible in amount $(2.3 \%)$.

As previously mentioned, whey was able to completely keep LPO activity within 4 days of storage. This can be explained that whey components support the activity of LPO. It has been studied that LPO activity might be inhibited by casein (Singh et al., 2009) while the casein has been removed from whey.

The remaining of LPO activity attached onto SPFF during 10 days of storage at $10^{\circ} \mathrm{C}$ is shown on Fig. 2b. PB was able to maintain $100 \%$ of LPO activity within 5 days of storage. The milk and whey were able to keep $100 \%$ of LPO activity within 3 days of storage. The elevation of storage time until 5 days in whey could keep enzyme activity although the remaining enzyme activity was small amount (10.08\%). Based on the availability, also since LPO was simply derived from whey, the storage of immobilized LPO in whey should keep its activity up to 5 days of storage. Therefore it is suggested that immobilized LPO should be stored in whey. 
Int. J. Dairy Sci., 9 (2): 56-62, 2014

\section{CONCLUSION}

The results can be concluded that LPO could be purified from whey using fraction number 21-30. One mililiter of LPO (35 $\mathrm{U} \mathrm{mL}^{-1}$ ) could be completely immobilized onto $0.6 \mathrm{~g} \mathrm{SPFF}$ or $0.9 \mathrm{~g}$ SPBB (immobilization efficiency was 100\%). Among various storage solution, whey was able to keep $100 \%$ of LPO activity up to 5 days of storage.

\section{ACKNOWLEDGMENTS}

This study was supported by funds from the Ministry of Research and Technology of Republic of Indonesia for the project "Insentif Riset SINAS" with Grant Project No. RT-2013-2163.

\section{REFERENCES}

Al-Baarri, A.N., M. Ogawa and S. Hayakawa, 2010. Scale-up studies on immobilization of lactoperoxidase using milk whey for producing antimicrobial agent. J. Indonesian Trop. Anim. Agric., 35: 185-191.

Al-Baarri, A.N., M. Hayashi, M. Ogawa and S. Hayakawa, 2011a. Effects of mono-and disaccharides on the antimicrobial activity of bovine lactoperoxidase system. J. Food Prot., 74: 134-139.

Al-Baarri, A.N., M. Ogawa and S. Hayakawa, 2011b. Application of lactoperoxidase system using bovine whey and the effect of storage condition on lactoperoxidase activity. Int. J. Dairy Sci., 6: $72-78$.

Al-Baarri, A.N., M. Ogawa, T. Visalsok and S. Hayakawa, 2012. Lactoperoxidase immobilized onto various beads for producing natural preservatives solution. J. Applied Food Technol., 1: 4-6.

Amersham-Bioscience, 2001. Use of sodium hydroxide for cleaning and sanitizing chromatography media and systems. Application Note 18-1124-57 AD, Process Chromatography, Amersham Bioscience, USA. http://risk.management6.com/Use-of-sodium-hydroxide-for-cleaning-andsanitizing-chromatography-download-w15138.pdf.

Boots, J.W. and R. Floris, 2006. Lactoperoxidase: From catalytic mechanism to practical applications. Int. Dairy J., 16: 1272-1276.

FAO/WHO, 2005. Benefits and potential risks of the lactoperoxidase system of raw milk preservation. Report of an FAO/WHO Technical Meeting, November 28-December 2, 2005, FAO Headquarters, Rome, Italy, pp: 1-73.

Fee, C.J. and A. Chand, 2006. Capture of lactoferrin and lactoperoxidase from raw whole milk by cation exchange chromatography. Separation Purification Technol., 48: 143-149.

Fweja, L.W.T., M.J. Lewis and A.S. Grandison, 2008. Challenge testing the lactoperoxidase system against a range of bacteria using different activation agents. J. Dairy Sci., 91: $2566-2574$.

Hayashi, M., S. Naknukool, S. Hayakawa, M. Ogawa and A.B.A. Ni'matulah, 2012. Enhancement of antimicrobial activity of a lactoperoxidase system by carrot extract and $\alpha$-carotene. Food Chem., 130: 541-546.

Oghaiki, N.A., F. Fonteh, P. Kamga, S. Mendi and H. Imele, 2007. Activation of the lsctoperoxidise system as a method of preserving raw milk in areas without cooling facilities. Afr. J. Food Agric. Nutr. Dev., 7: 1-14.

Seifu, E., E.M. Buys and E.F. Donkin, 2004. Quality aspects of Gouda cheese made from goat milk preserved by the lactoperoxidase system. Int. Dairy J., 14: 581-589. 
Seifu, E., E.M. Buys and E.F. Donkin, 2005. Significance of the lactoperoxidase system in the dairy industry and its potential applications: A review. Trends Food Sci. Technol., 16: 137-154.

Singh, A.K., N. Singh, S. Sharma, K. Shin and M. Takase et al., 2009. Inhibition of lactoperoxidase by its own catalytic product: Crystal structure of the hypothiocyanate-inhibited bovine lactoperoxidase at 2.3-A resolution. Biophys. J., 96: 646-654.

Touch, V., S. Hayakawa, S. Yamada and S. Kaneko, 2004. Effects of a lactoperoxidase-thiocyanatehydrogen peroxide system on Salmonella enteritidis in animal or vegetable foods. Int. J. Food Microbiol., 93: 175-183.

Zhou, Y. and L.T. Lim, 2009. Activation of lactoperoxidase system in milk by glucose oxidase immobilized in electrospun polylactide microfibers. J. Food Sci., 74: C170-C176. 


\section{Alert \\ HOME \\ JOURNALS \\ AUTHORS \\ SUBSCRIBERS}

\section{International Journal of Dairy Science}

Publisher: Academic Journals Inc., USA

\begin{tabular}{|c|c|}
\hline $\begin{array}{l}\text { International Journal } \\
\text { of } \\
\text { D A I R Y } \\
\text { S C I E N C E E }\end{array}$ & $\begin{array}{l}\text { International Journal of Dairy Science is a high quality peer-reviewed scientific journal } \\
\text { dedicated to publish cutting edge research work on all aspects of dairy sciences. Scope } \\
\text { of the journal includes: Biochemistry, breeding, economics, engineering, environment, } \\
\text { food science, genetics, microbiology, nutrition, pathology, physiology, processing, public } \\
\text { health quality assurance, sanitation, microbiology and bacteriology. }\end{array}$ \\
\hline 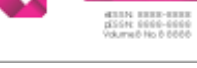 & $\begin{array}{l}\text { Submit your next paper to International Journal of Dairy Science via online submission } \\
\text { system. }\end{array}$ \\
\hline & or-in-Chief: Hussein Azzaz Murad \\
\hline
\end{tabular}
pISSN: $1811-9743$

\section{Editor-in-Chief}

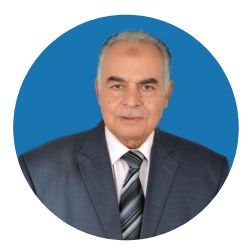

Hussein Azzaz Murad National Research Center, Egypt

REGIONAL EDITORS

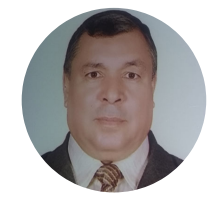

Abd El-Kader Mahmoud Kholif National Research Centre, Egypt

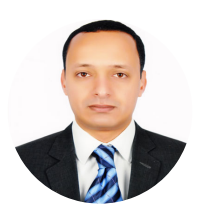

Ahmed Eid Kholif National Research Centre, Egypt

\section{ASSOCIATE EDITORS}

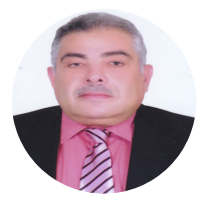

Othman El-Mahdy Sayed Othman National Research Center, Egypt

\section{Navigation}

G Online First

[ Current Issue

Previous Issues

Editorial Board

Submit a Manuscript

Guide to Authors

Article Processing Charges

Subscribe to E-alerts

\section{International Journal of Dairy Science}

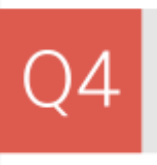

Animal Science and Zoology best quartile

SJR 2018

0.18

powered by scimagojr.com

\section{Google Scholar}

\section{Indexed In}

\begin{tabular}{ll}
0 & ASCI-Database \\
\hline 0 & $\underline{\text { Asian Digital Library. }}$ \\
\hline$\square$ & $\underline{\text { Cambridge Scientific Abstract }}$ \\
\hline$\square$ & $\underline{\text { Chemical Abstract Services }}$ \\
\hline$\square$ & $\underline{\text { FSTA }}$ \\
\hline$\square$ & $\underline{\text { Google Scholar }}$ \\
\hline$\square$ & $\underline{\text { SCIMAGO }}$ \\
\hline
\end{tabular}




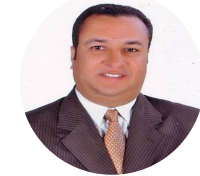

Dr. Ashraf Mohamed Abdel Rahman Abu-Seida Cairo University, Egypt

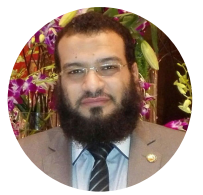

Mostafa Sayed Abd El-Latif Khattab

National Research Center, Egypt

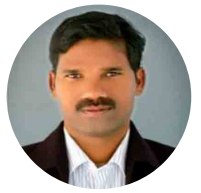

Veerasamy Sejian

National Institute of Animal Nutrition and Physiology, India

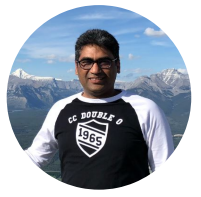

Sumeet Sharma University of Alberta, Canada

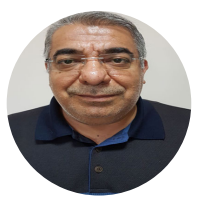

Karakus Kadir Yuzuncu Yil University, Turkey

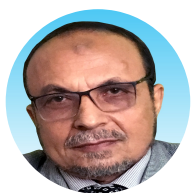

Dr. Wahid Mohamed Ahmed National Research Center, Egypt

\section{TECHNICAL EDITORS}

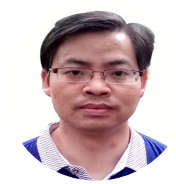

Jinming Huang

Shandong Academy of Agricultural Sciences, China

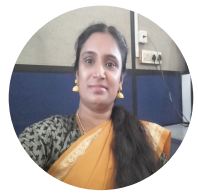

A. Yasotha

Madras Veterinary College, India

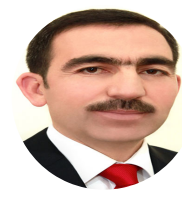

Ebubekir Ceylan Hakkari University, Turkey

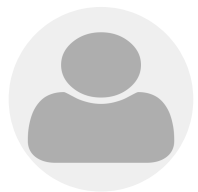

Karima Galal Abdel Hameed South Valley University, Egypt

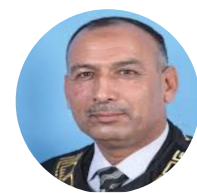

Zuhair Bani Ismail Purdue University, USA
Mervat Ibrahim Foda National Research Center, Egypt

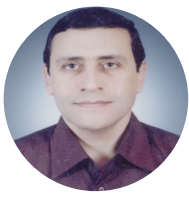

Dr. Alaa Abdel-Moneam Ghazy Mohamed

National Research Center, Egypt

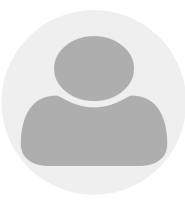

Suleyman Cilek Kirikkale University, Turkey

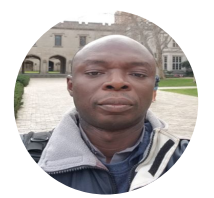

Richard Osei Amponsah University of Ghana, Ghana

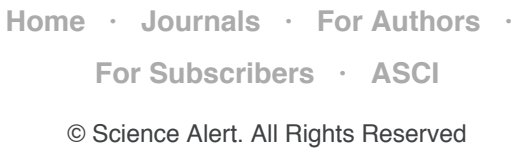

(C) Science Alert. All Rights Reserved 


\title{
International Journal of Dairy Science
}

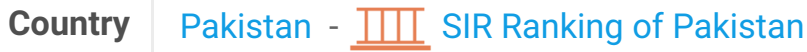 \\ Subject Area and \\ Category \\ Agricultural and Biological Sciences \\ Animal Science and Zoology \\ Veterinary \\ Food Animals
}

14

Publisher Asian Network for Scientific Information

\author{
Publication type Journals \\ ISSN $\quad 18119743,18119751$ \\ Coverage 2006-ongoing
}

Scope International Journal of Dairy Science is dedicated to disseminate the international original research on all aspect of dairy science. International Journal of Dairy Science publishes original scientific research on all aspects of dairy science including: animal husbandry, the physiology, biochemistry and endocrinology of lactation, milk production, composition, preservation, processing and separation, biotechnology and food science, properties of milk proteins and other components, dairy products such as cheese, fermented milks and spreads, relevant studies in bacteriology, enzymology and immunology, the use of milk products in other foods; and the development of methods relevant to these subjects.

\section{Homepage}

Join the conversation about this journal

\section{Quartiles}

Animal Science and Zoology
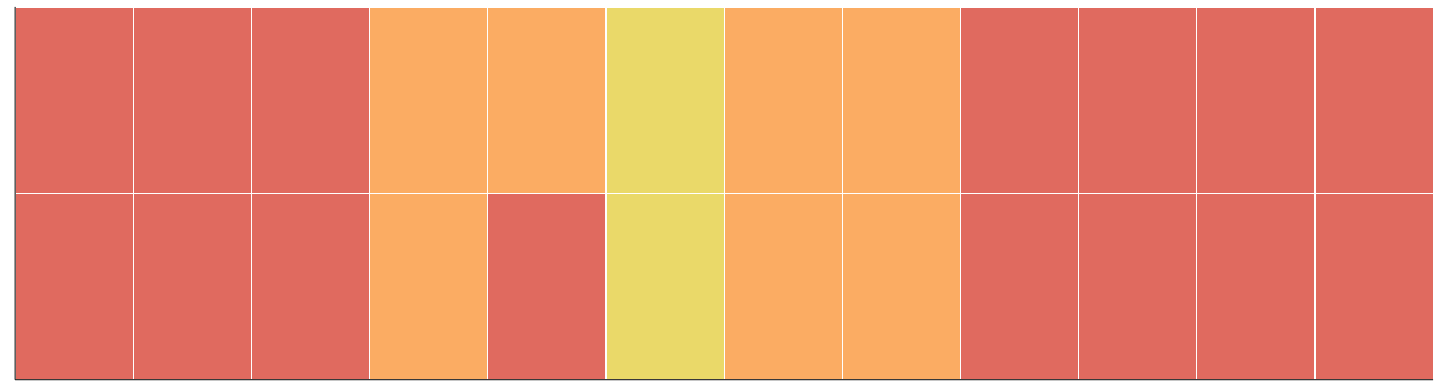

2007 


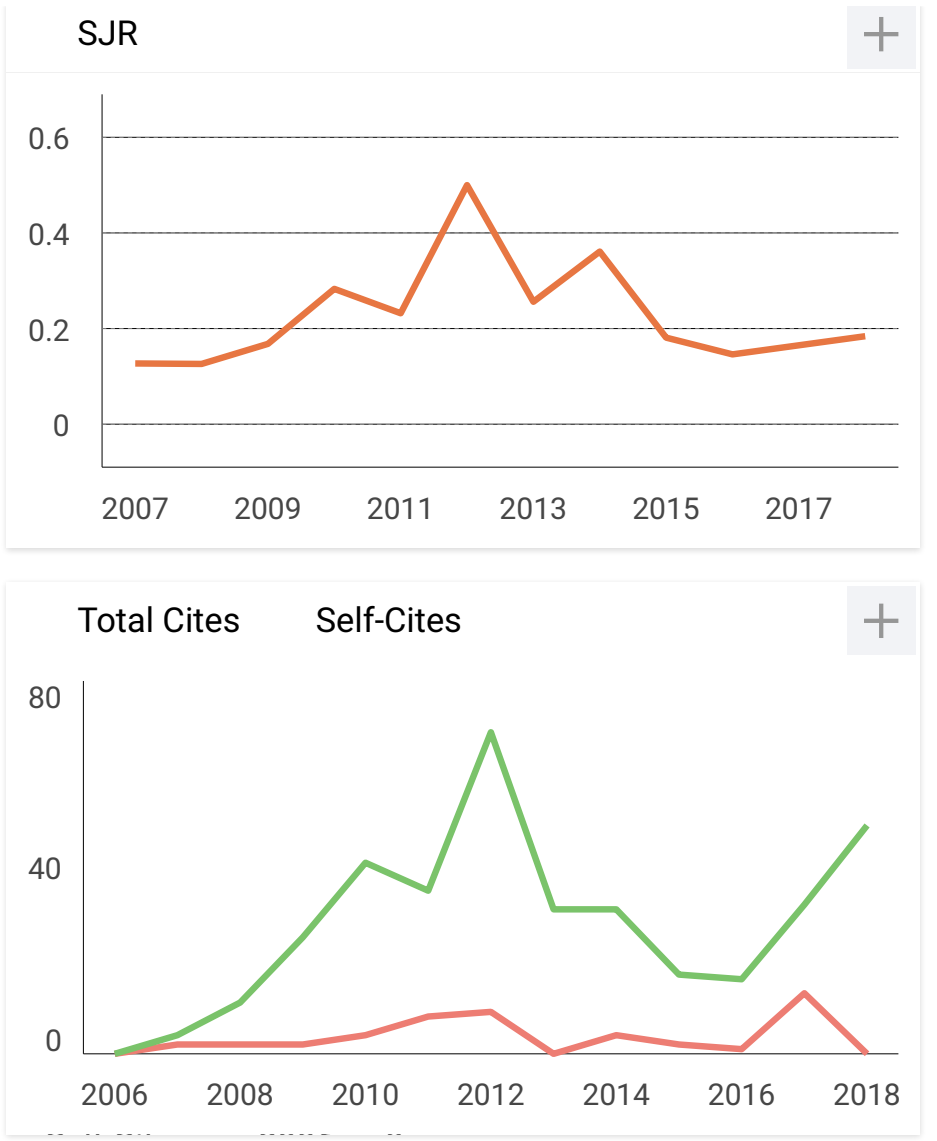

\section{External Cites per Doc Cites per Doc}
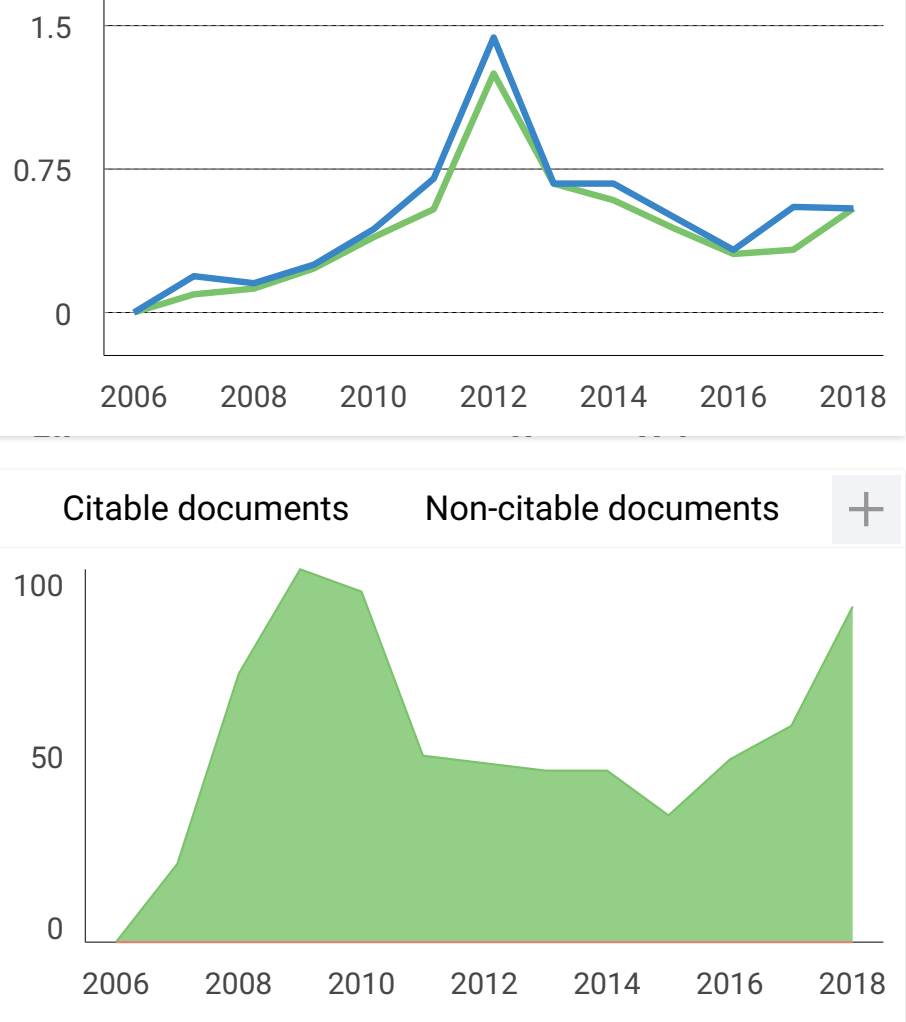

Show this widget in your own website

Just copy the code below and paste within your html code:
Citations per document

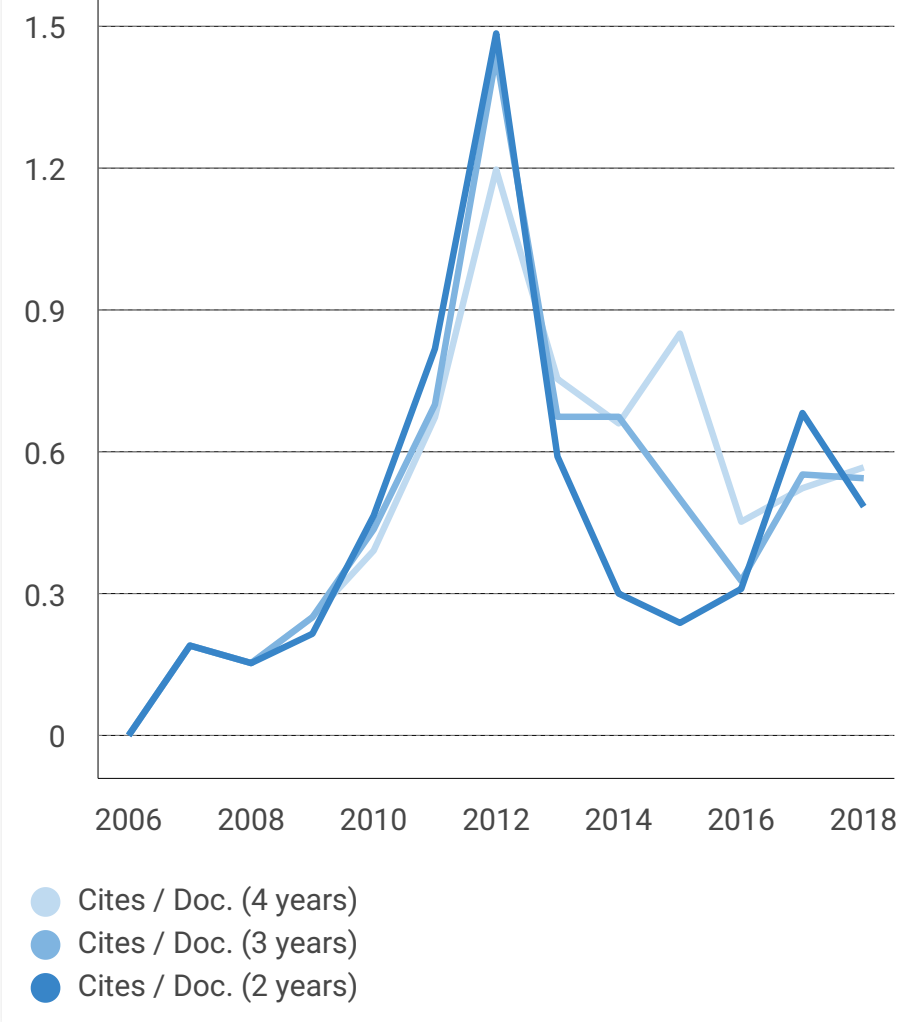

\% International Collaboration

20

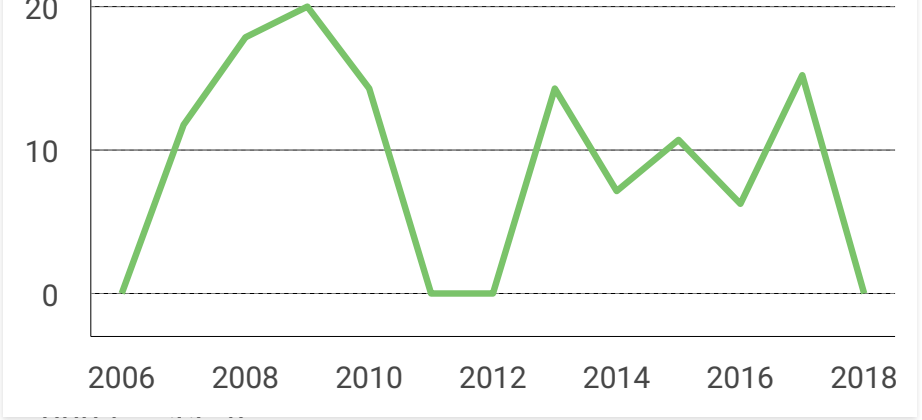

Cited documents Uncited documents

100

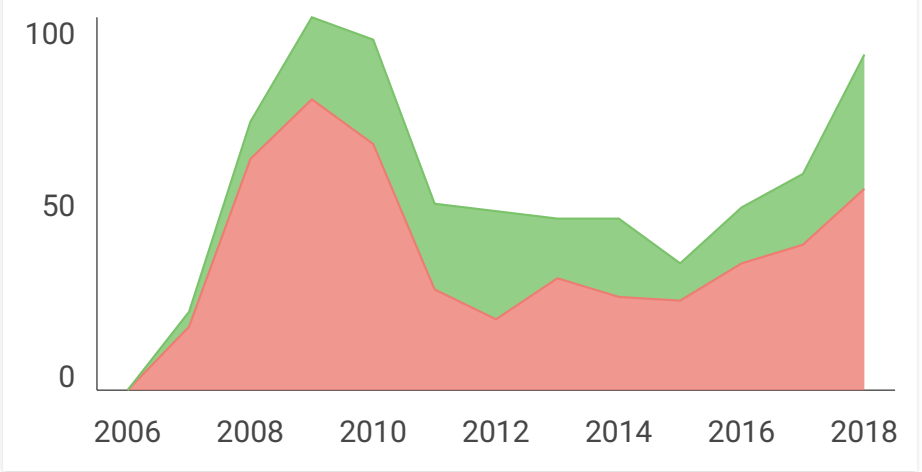




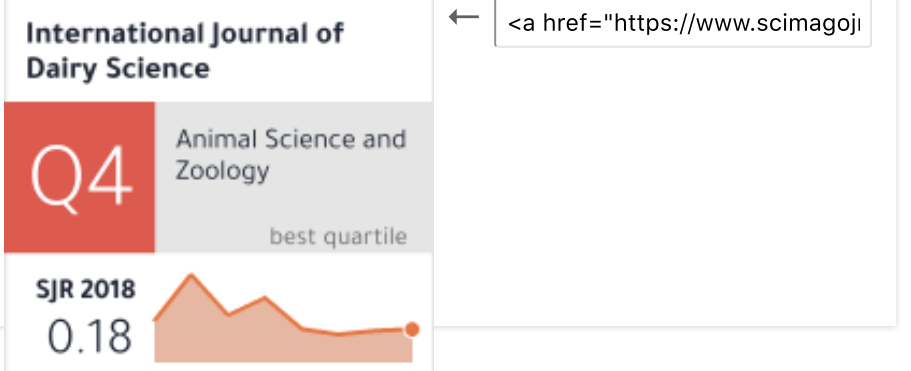

nawarad huecrimanoin som 


\section{Scopus Preview}

\section{Sources}

Title $\checkmark$ Enter title

Title: International Journal Of Dairy Science $\times$

i CiteScore metrics for journals and serials

CiteScore metrics from Scopus are:

- Comprehensive

- Transparent

- Current and free

Use this page to find a source and view associated metrics. Use qualitative as well as quantitative metrics when presenting your research impact. Always use more than one quantitative metric. Learn more about CiteScore.
Filter refine list

\section{Apply Clear filters}

\section{Display options}

$\square$ Display only Open Access journals

Counts for previous 3 years

No minimum selected

Minimum citations

Minimum documents

Citescore highest quartile

Show only titles in top 10

percent

lst quartile

2nd quartile

3rd quartile

4th quartile

\section{Source type}

Journals

Book Series

Conference Proceedings

Trade Publications

Apply Clear filters

\section{1 result

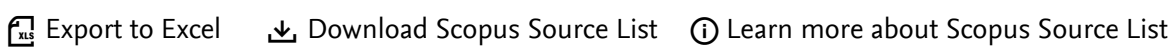

View metrics for year: 2018

Source title $\downarrow$

CiteScore $\downarrow$ Highest percentile $\downarrow$

Citations Documents \% Cited $\downarrow$ SNIP $\downarrow$ $2018 \downarrow \quad 2015-17 \downarrow$

\begin{tabular}{lllllll}
\hline International Journal of Dairy & 0.56 & $32 \%$ & 50 & 90 & 42 & 0.741 \\
Science & & & \\
& & &
\end{tabular}

\section{About Scopus}

What is Scopus

\section{Customer Service}




\section{Scopus}

\section{1 document result}

Search within results...

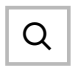

Refine results

Limit to Exclude

Access type (i)

$\wedge$

Open Access

(1) >

Year

2014

(1) >

\section{Author name}

Al-Baarri, A.N.M.

Legowo, A.M.

(1) $>$

(1) >

Mulyani, S.

(1) >

Nawangsari, D.N

(1) >

Priyo Bintoro, V.P.

(1) >

\section{Subject area}

Agricultural and
Biological Sciences

Veterinary

(1) $>$
叫 Analyze search results

Show all abstracts Sort on: Date (newest)
All $\vee$ RIS export $\vee$ Download $\quad$ View citation overview $\quad$ View cited by Save to list $\quad$..•

吕四哭

Document title

Authors

Year Source

Cited by

1 Resistance of immobilized lactoperoxidase activity from bovine whey against storage solutions

Open Access

Nawangsari, D.N., Al-Baarri, A.N., Mulyani, S., Legowo, A.M., Priyo Bintoro, V.P.

2014 International Journal of Dairy Science 9(2), pp. 56-

62

\section{View abstract $\vee$ View at Publisher Related documents}

\section{Display: $20 \quad \checkmark$}

results per page

\begin{tabular}{lc} 
Publication stage & $\checkmark$ \\
\hline Document type & $\checkmark$ \\
\hline Source title & $\checkmark$ \\
\hline Keyword & $\checkmark$ \\
\hline Affiliation & $\checkmark$ \\
\hline Funding sponsor & $\checkmark$ \\
\hline Country/territory & $\wedge$ \\
$\begin{array}{l}\text { Indonesia } \\
\text { Source type }\end{array}$ & $(1)>$ \\
\hline Language & $\checkmark$ \\
\hline
\end{tabular}

Limit to Exclude 


\section{BUKTI KORESPONDENSI SAYA}




\section{COVER LETTER FOR SUBMISSION OF NEW MANUSCRIPTS}

To International Journal of Dairy Science's Editor

\section{Subject: SUBMISSION OF NEW MANUSCRIPT FOR EVALUATION}

I am enclosing herewith a manuscript entitled "Resistance of Immobilized Lactoperoxidase Activity From Bovine Whey Against Storage Solutions" submitted to "International Journal of Dairy Science" for possible evaluation.

With the submission of this manuscript I would like to undertake that the above mentioned manuscript has not been published elsewhere, accepted for publication elsewhere or under editorial review for publication elsewhere; and that my Institute's [Diponegoro University, Semarang, Indonesia] representative is fully aware of this submission.

Select Type of Submitted manuscript:

- Original Article $\mathrm{V}$

- Review Article

- Mini-Review

- Short Communication

- Clinical Article

- Perspective

- Editorial

- Anyother (specify the type of manuscript) 


\section{For the Editor-in-Chief,}

I would like to disclose the following information about the project:

RESISTANCE OF IMMOBILIZED LACTOPEROXIDASE ACTIVITY FROM BOVINE WHEY AGAINST STORAGE SOLUTIONS

The research project was conducted under the supervision of:

1. Ahmad Ni'matullah Al-Baarri, PhD (team leader, corresponding author)

2. Sri Mulyani, MP.

3. Prof. Anang Mohamad Legowo

4. Prof. V. Priyo Bintoro

and the project was run as my M.Sc project

This research project was conducted from July 2013 to February 2013

My Research Project was fully sponsored by Ministry of Research and Technology of Republic of Indonesia with grant number RT-2013-2163.

Detail of the each author with his/her contribution in this paper is as under:

\begin{tabular}{|l|l|}
\hline Name of the author and e-mail ID & Types of contribution \\
\hline Ahmad Ni'matullah Al-Baarri, PhD & Co-author and technical supervisor \\
\hline Sri Mulyani & Co-author and technical supervisor \\
\hline Prof. Anang Mohamad Legowo & Co-author and data analysis \\
\hline Prof. V. Priyo Bintoro & Co-author and data interpretation \\
\hline
\end{tabular}

I would also like to share the following information with Editor-in-Chief

I have the following similar manuscripts already published from this project:

No, I have no article yet in this journal.

This is the first original article, but my supervisor has an accepted article

on International Journal of Dairy Science 6 (1): 72-78,2011

entitled:

Application of Lactoperoxidase System Using Bovine Whey and the Effect of Storage Condition on Lactoperoxidase Activity

My supervisor was also published other article in other international journal.

For quick understanding about the importance of the project following are the significant findings of my submitted article?

Both of SP-Sepharose (Fast Flow and Big Beads) have been known as ion exchange resins for immobilizing lactoperoxidase. Since the price of both compounds are expensive, the efficient 
use is required. This article showed the optimum amount of lactoperoxidase might be attached to resin and the analysis of enzyme activity in various storage solutions.

How findings of this research work are unique in their nature?

Many investigator used ion exchange resin to immobilize lactoperoxidase, however none investigator mentioned the optimum condition for immobilizing lactoperoxidase.

This research answered those questions and provide the information for the optimum use of sepharose resin to immobilize lactoperoxidase.

Since in the large scale production and utilization of lactoperoxidase is required, the storage solution are the key to keep the enzyme activity. This article showed the best storage solution to keep the enzyme activity.

A paragraph explaining why your manuscript is appropriate for the selected journal

This original article is about lactoperoxidase that naturally obtained from fresh milk. The enzyme has great benefit to the long time preservation of milk and dairy products. Since this journal concerns about dairy science, I believe this journal is appropriate for this article. 
We have received the response from reviewer 1 and reviewer 2 to our article, however we found the question from reviewer 2 only:

Al Baarri,2011 missed, Also the result of LPO activity why not presented in a table Also The captions of the figures must be written at the top of the figures and must be clear and explain the figures.

\section{Our responses:}

1. Al-Baarri, 2011 has been changed to Al-Baarri, 2011a. We are sorry, it should be added with "a" after "2011"

2. LPO activity did not appear in a table since we would like to show the differences between treatments (storage). We believe that the description through percentage in a figure is much easier to be understood

3. The caption has been moved into the top of figure and the explanation of figure has been completed.

Sincerely,

Ahmad Ni'matullah Al-Baarri
Formatted: Left, Indent: Left: $1 \mathrm{~cm}$, Right: $1.92 \mathrm{~cm}$

Formatted: Font: Not Bold

Formatted: Left

Formatted: Left, Numbered + Level: $1+$ Numbering Style: 1 , $2,3, \ldots+$ Start at: $1+$ Alignment: Left + Aligned at: $0.63 \mathrm{~cm}$ + Indent at: $1.27 \mathrm{~cm}$

Formatted: Left

Formatted: Font: Not Bold 
COVER LETTER FOR SUBMISSION OF NEW MANUSCRIPTS

$\underline{\text { To International Journal of Dairy Science's Editor }}$

\section{SUbject: SUBMISSION OF NEW MANUSCRIPT FOR EVALUATION}

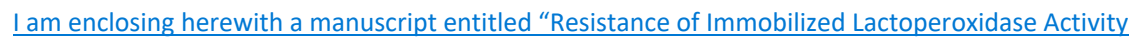
From Bovine Whey Against Storage Solutions" submitted to "International Journal of Dairy Science" for possible evaluation.

With the submission of this manuscript I would like to undertake that the above mentioned manuscript has not been published elsewhere, accepted for publication elsewhere or under editorial review for publication elsewhere; and that my Institute's [Diponegoro University, Semarang, Indonesia] representative is fully aware of this submission.

Select Type of Submitted manuscript:

- Original Article $\mathrm{V}$

- Review Article

- Mini-Review

- Short Communication

- Clinical Article

- Perspective

- Editoriat

- Any other (specify the type of manuscript) 


\section{For the Editor-in-Chief,}

I would like to disclose the following information about the project: RESISTANCE OF IMMOBILIZED LACTOPEROXIDASE ACTIVITY FROM BOVINE WHEY AGAINST STORAGE SOLUTIONS

The research project was conducted under the supervision of:
1. Ahmad Ni'matullah Al-Baarri, PhD
2. Sri Mulyani, MP.
3. Prof. Anang Mohamad Legowo
4. Prof. V. Privo Bintoro

and the project was run as my M.Sc project

This research project was conducted from July 2013 to February 2013

My Research Project was fully sponsored by Ministry of Research and Technology of Republic of Indonesia with grant number RT-2013-2163.

Detail of the each author with his/her contribution in this paper is as under:

\begin{tabular}{|l|l|}
\hline$\underline{\text { Name of the author and e-mail ID }}$ & $\underline{\text { Types of contribution }}$ \\
\hline$\underline{\text { Ahmad Ni'matullah Al-Baarri, PhD }}$ & $\underline{\text { Co-author, and article content }}$ \\
\hline$\underline{\text { Sri Mulyani }}$ & $\underline{\text { Co-author and technical supervisor }}$ \\
\hline$\underline{\text { Prof. Anang Mohamad Legowo }}$ & $\underline{\text { Co-author, data analysis, article interpretation }}$ \\
\hline$\underline{\text { Prof. V. Priyo Bintoro }}$ & $\begin{array}{l}\text { Co-author, data interpretation, English } \\
\text { guidance }\end{array}$ \\
\hline
\end{tabular}

$\underline{\text { I would also like to share the following information with Editor-in-Chief }}$

I have the following similar manuscripts already published from this project:

No, I have no article yet in this journal.

This is the first original article, but my supervisor has an accepted article

on International Journal of Dairy Science 6 (1): 72-78,2011

entitled:

Application of Lactoperoxidase System Using Bovine Whey and the Effect of Storage Condition on Lactoperoxidase Activity

My supervisor was also published other article in other international journal.

For quick understanding about the importance of the project following are the significant findings of my submitted article?

Both of SP-Sepharose (Fast Flow and Big Beads) have been known as ion exchange resins for immobilizing lactoperoxidase. Since the price of both compounds are expensive, the efficient use is required. This article showed the optimum amount of lactoperoxidase might be attached to resin and the analysis of enzyme activity in various storage solutions. 
How findings of this research work are unique in their nature?

Many investigator used ion exchange resin to immobilize lactoperoxidase, however none investigator mentioned the optimum condition for immobilizing lactoperoxidase.

This research answered those questions and provide the information for the optimum use of sepharose resin to immobilize lactoperoxidase.

Since in the large scale production and utilization of lactoperoxidase is required, the storage solution are the key to keep the enzyme activity. This article showed the best storage solution to keep the enzyme activity.

A paragraph explaining why your manuscript is appropriate for the selected journal

This original article is about lactoperoxidase that naturally obtained from fresh milk. The enzyme has great benefit to the long time preservation of milk and dairy products. Since this journal concerns about dairy science, I believe this journal is appropriate for this article. 


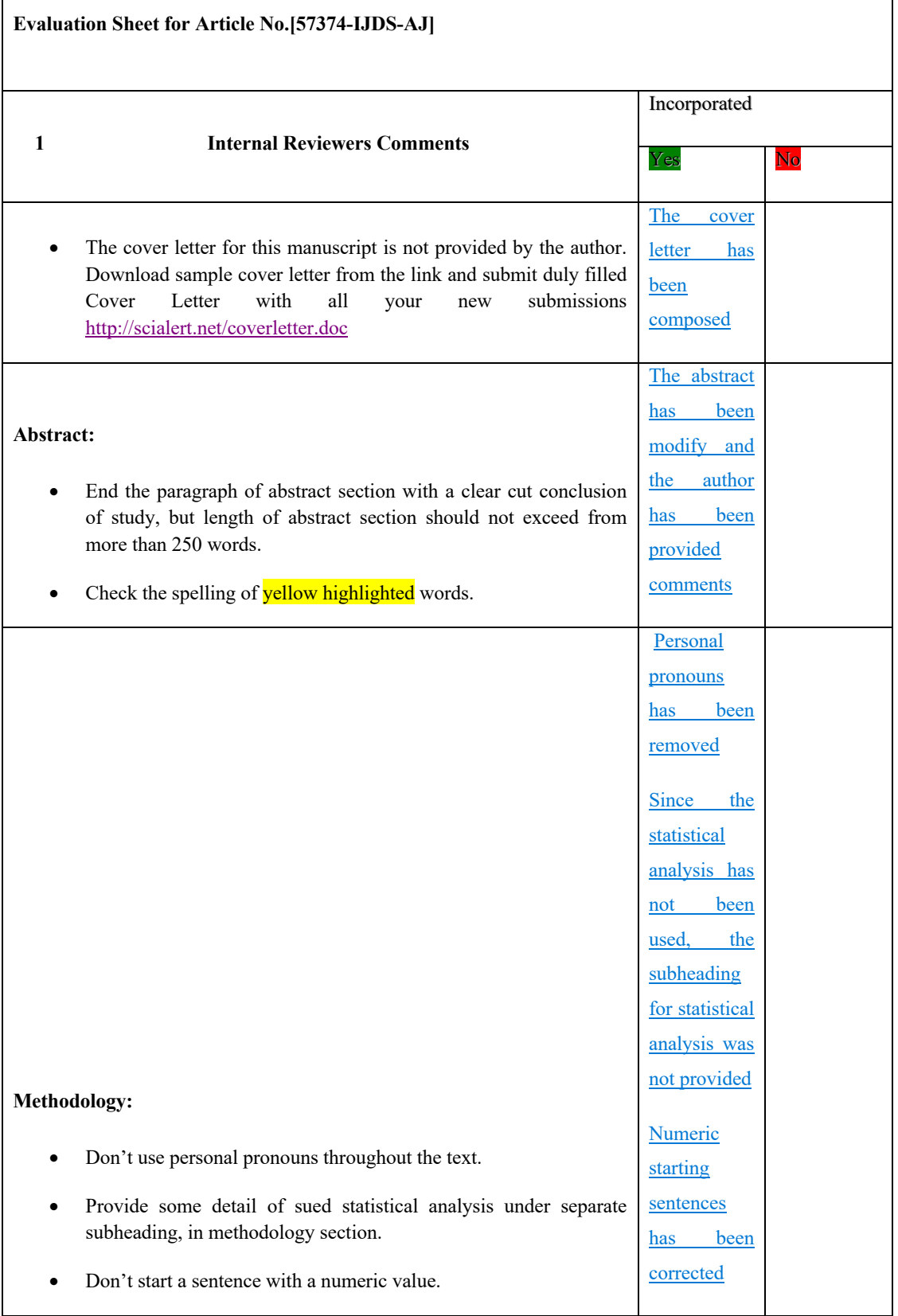




\section{Results and Discussion:}

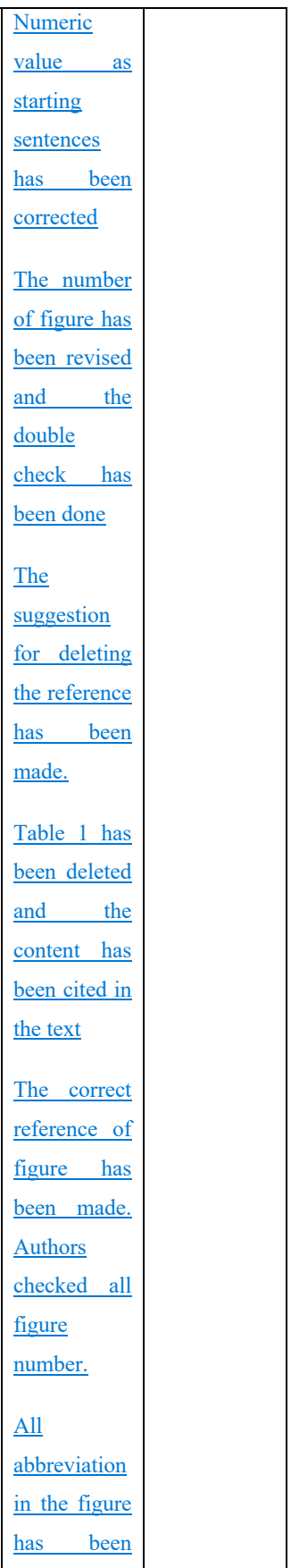

- Some numeric values mentioned in text are not in accordance with their respective tabular data. For your convenience some of those values have been yellow highlighted. Correct all data irregularities by comparing numeric values given in text with their respective tabular data.

- Author has cited Figure 3 in text but didn't provide it in the submitted manuscript. Provide this missing figure and make sure that all figures have been cited in text in consecutive numerical order. All cited figures must be presented in the manuscript and all presented figures must be cited in the text at appropriate places along with their suitable explanation.

- Provide correct reference of all figures in text.

- Delete table 1 and explain its data in text, as it does not contain significant amount of data that needs to be presented in tabular form.

- Define all abbreviations used in figures in their respective captions.

- The given captions of your figures 1 and 2 have not been written properly. A figure should be self-explanatory and its caption plays a very important role in this regard. Provide such captions for all these figures in which all of their main parts have been properly explained.

- Assign an alphabet to each sub-part of Figure 2 and explain each figure part in figure caption by referring to its respective alphabet. A figure should be self-explanatory and its caption plays a very important role in this regard. Provide such caption in which al main parts of this figure have been properly explained. All cited figures must be presented in the manuscript and all presented figures must be cited in the text at appropriate places along with their suitable explanation.

- In submitted manuscript Figure 2 has been presented but Autho didn't cite this figure in text. Cite this figure in text at appropriate place with suitable explanation and make sure that all figures have been cited in text in consecutive numerical order. All cited figures must be presented in the manuscript and all presented figures must be cited in the text at appropriate places along with their suitable explanation. 


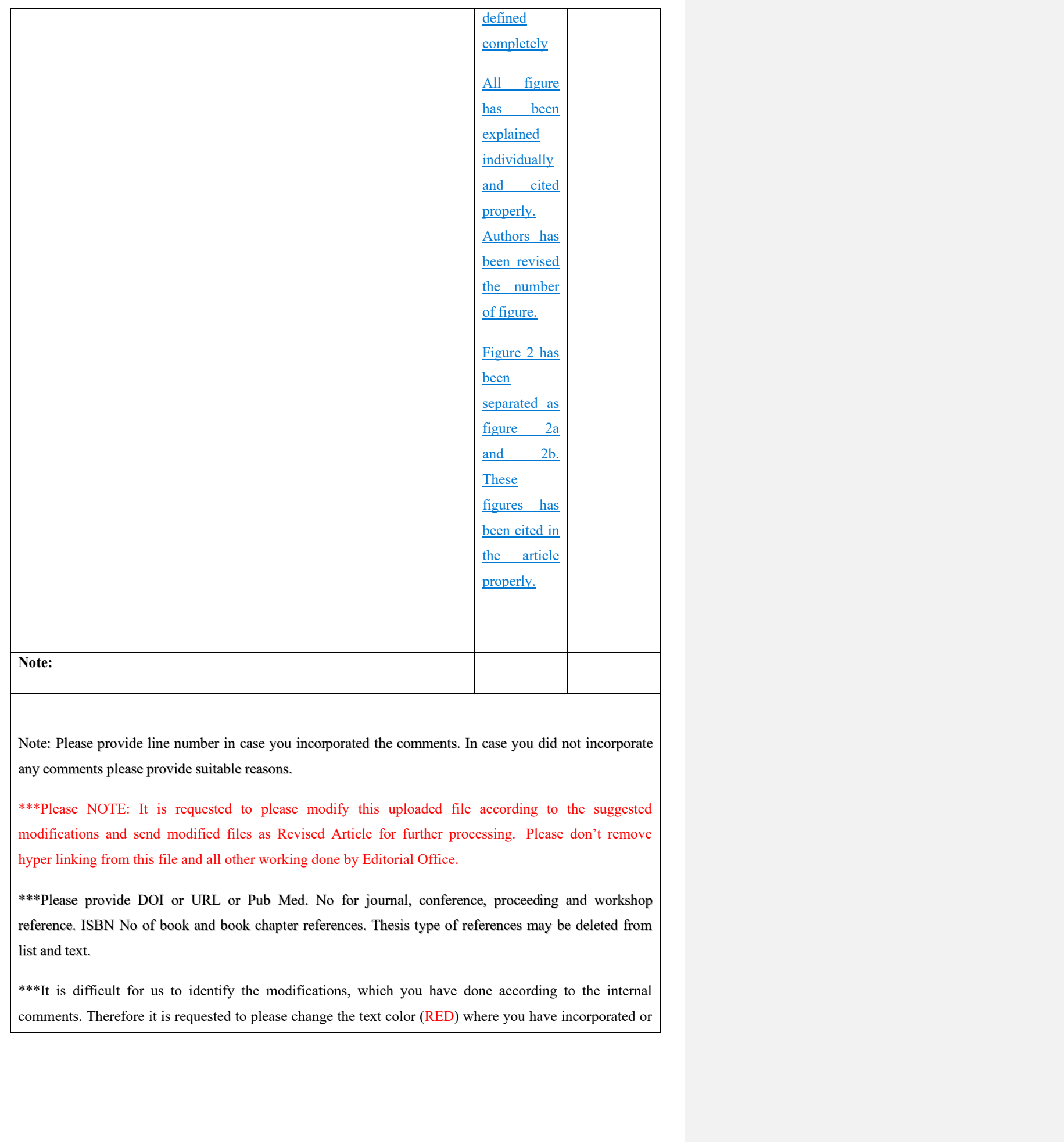




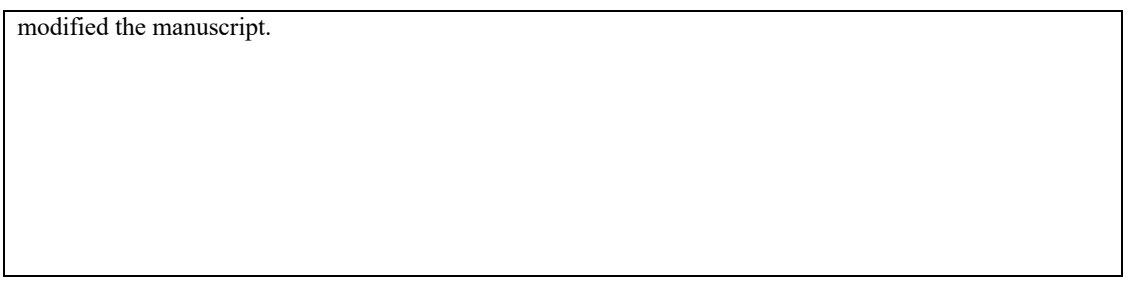




\section{Ref\#17 \\ RESISTANCE OF IMMOBILIZED LACTOPEROXIDASE ACTIVITY FROM BOVINE WHEY AGAINST STORAGE SOLUTIONS}

\author{
Dwi Novrina Nawangsari ${ }^{1)}$, Ahmad Ni'matullah Al-Baarri ${ }^{2}{ }^{2}, S r i$ Mulyani' ${ }^{2}$, Anang \\ Mohamad Legowo ${ }^{2}$, V. Priyo Bintoro ${ }^{2}$ )
}

1)Department of Animal Product Technology; Faculty of Animal and Agricultural Sciences; Diponegoro University, Semarang, Indonesia

2)Department of Food Technology, Faculty of Animal and Agricultural Sciences; Diponegoro University, Semarang, Indonesia

\begin{abstract}
Lactoperoxidase (LPO) could be simply obtained from whey through immobilization using a cation exchange resin of SP Sepharose. LPO received high attention since the antimicrobial properties of LPO system (LPOS) that are consisted of $\mathrm{LPO}, \mathrm{SCN}^{-}$, and $\mathrm{H}_{2} \mathrm{O}_{2}$ was able to generate $\mathrm{OSCN}^{-}$for strong antimicrobial agents. This study was done to analyze the immobilization efficiency of LPO onto two types of sepharose: SP-Sepharose Fast Flow (SPFF) and SP-Sepharose Big Beads (SPBB). The remaining of LPO's activity (\%) against storage solution was also observed. The whey was obtained from bovine skimmed milk that was coagulated using rennet and acid lactic. The LPO was obtained from whey using SPFF. To analyze the resistence of enzyme activity, the immobilized LPO was stored in pure water, phosphate buffer, milk, and whey at $10^{\circ} \mathrm{C}$. The activity of LPO was monitored for 10 days. The result indicates that the LPO could be purified from whey and single band has been detected using electrophoresis method. The obtained LPO $(35 \mathrm{U} / \mathrm{ml})$ was attached onto SPFF and SPBB. Maximum immobilization efficiency has been achieved by $0.6 \mathrm{~g}$ SP-FF and $0.9 \mathrm{~g}$ SP-BB, LPO activity of the immobilized LPO were able to be kept until 5 days when it was stored in whey. Other storage solution remained various LPO activity during storage. This research concluded that IE of LPO attached onto sepharoses might be reached variously depended on the sepharose type and whey as LPO source might be used for maintaining LPO activity.
\end{abstract}

Key words: Lactoperoxidase, SP Sepharose Fast Flow, SP Sepharose Big Beads, immobilization, remaining activity.

\section{Deleted: ${ }^{1}$}

Deleted:

Deleted: and

Commented [ANA1]: Please allow us to add the co-authors since this author has a big contribution to our experiments and article writing. The contribution of authors have been mentioned in cover letter.

Commented [02]: The cover letter for this manuscript is not provided by the author. Download sample cover letter from the link and submit duly filled Cover Letter with all your new submissions http://scialert.net/coverletter.doc

Commented [ANA3]: Cover letter has been made and author has sent this cover letter along with this article.

Commented [04]: End the paragraph of abstract section with a clear cut conclusion of study, but length of abstract section should not exceed from more than 250 words.

Commented [ANA5]: Cover letter has been added and sent via email

Commented [06]: Check the spelling of yellow highlighted words.

Deleted: remaining

Deleted: immobilized LPO

Deleted: It was concluded that

Deleted: were able to achieved $100 \%$ of immobilization eficiency (IE). LPO

Deleted: onto Sepharoses 


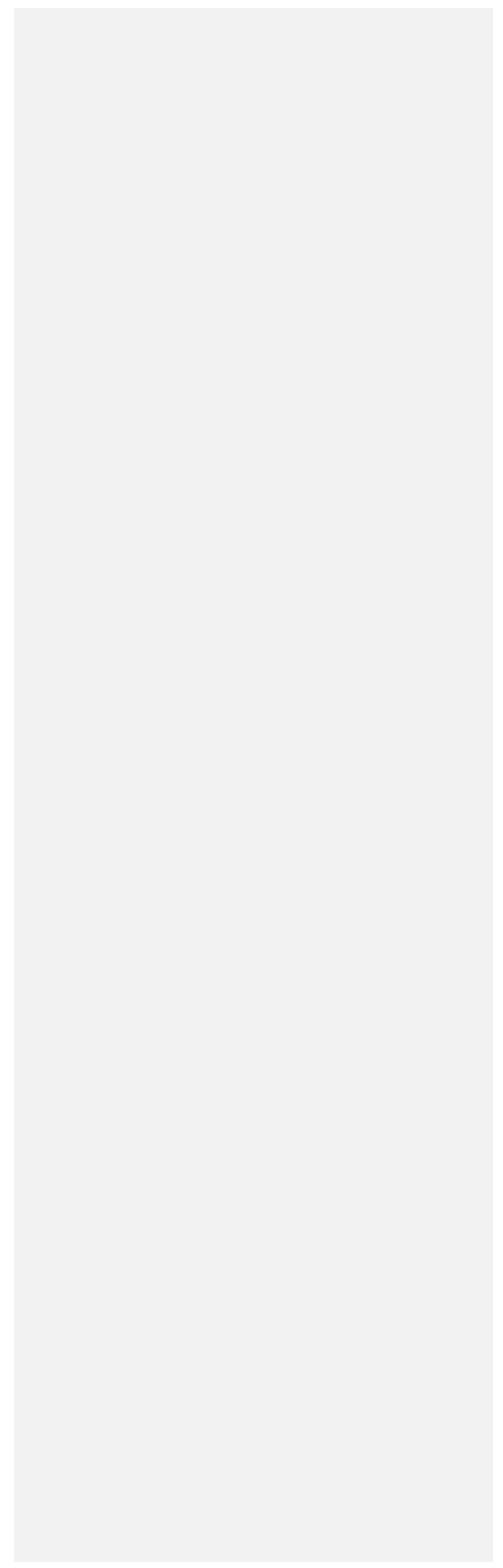




\section{INTRODUCTION}

Lactoperoxidase (LPO), together with $\mathrm{SCN}^{-}$and $\mathrm{H}_{2} \mathrm{O}_{2}$ have been understood to generates intermediate product of $\mathrm{OSCN}^{-}$as antibacterial agent that has a broad spectrum of antimicrobial effects against bacteria, fungi and viruses. This antibacterial agent could be produced if these three components exist in the medium (Seifu et al., 2005, Al-Baarri, 2011a). LPOS has been widely used as a preservative in dairy products and nondairy products (Seifu et al., 2004, Touch et al., 2004, FAO/WHO, 2005, Boots and Floris, 2006, Oghaiki et al, 2007, Fweja et al., 2008, $\underline{\text { Al-Baarri et al., 2011a). }}$.

It has been understood that whey contains large number of LPO therefore purification method of LPO from whey has been well developed (Touch et al., 2004, Zhou and Lim, 2009, Al-Baarri et al., 2010). SP-Sepharose has been known to provide beneficial effect for the immobilization efficiency since SP-Sepharose almost completely immobilized LPO and reusable (Al-Baarri et al., 2010). Although LPOS was widely used in food application but it still remained the problem of its expensiveness, therefore the immobilization of LPO was needed for the reuse of LPO.

SP Sepharose has been known as immobilization agent for capturing lactoperoxidase (Fee and Chand, 2006; Hayashi et al., 2012). SP Sepharose Fast Flow (SPFF) and SP Sepharose Big Beads (SPBB) were the common resin for immobilization since the they provide simply application, long term of use, and easy for reuse (Amersham-Bioscience, 2001). If compare to other immobilization agent such as chitosan, SP Sepharoses showed higher capturization of lactoperoxidase (Al-Baarri et al., 2012). In the other hand, SP Sepharose application for immobilization of LPO resulting in the much more expensive of the use of LPO, therefore the efficient use of SP Sepharose to immobilize LPO is required. Based on related literatures, there was no documentation for the efficient use of LPO immobilization using SP Sepharose, therefore this research has been done for analyzing the maximum capturization of LPO onto SP Sepharose. This information might provide the benefit for minimum use of SP Sepharose for LPO immobilization. Since the immobilized LPO allowed the reuse of enzyme, the appropriate storage solution for keeping the enzyme activity is needed. To answer this, this research has also been done for analyzing the remaining of LPO activity after storage.

\section{MATERIALS AND METHODS}

Materials

\section{Deleted: s}

\section{Deleted: appropriate}

Commented [08]: Don't use personal pronouns throughout the
text.
Deleted:

Commented [ANA9]: I do not have idea to replace this word, so, I did not change this word.

Commented [010]: Provide some detail of sued statistical analysis under separate subheading, in methodology section.

Deleted: descriptive analysis was used for describing activity of LPO in all treatment. \%? 


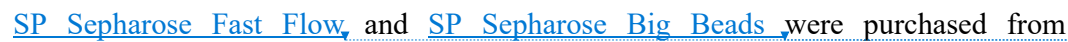
Amersham Pharmacia Biotech, Sweden (Lot. No.10029743 and No. 10081054, respectively). Microbial derived rennet was purchased from Singapore and ABTS or 2,20-azino-bis (3ethylbenz-thiazoline-6-sulphonic acid) was obtained from Kagawa Science (Lot No. 7ROZCEC) Tokyo Chemical, Industry Co. Ltd. Japan. Cow's milk was obtained from Faculty of Animal and Agricultural Sciences's farm, Diponegoro University, Semarang, Indonesia. The spectrophotometer (Mini UV-1800, Schimadzu, Japan) was used for analysis enzyme activity. Unless other compounds specified, all other compounds were reagent grade.

\section{Preparation of whey}

The whey was prepared as method performed by Al-Baarri et. al. (2011b) without any modification.

\section{LPO Immobilization from Whey}

The procedure for immobilization of LPO was conducted as the method that was performed by Al-Baarri et al., 2010 with minor modifications. SP Sepharose Fast Flow (SPFF) was used as agent for LPO immobilization from whey. Whey at the volume of 1800 $\mathrm{ml}$ was eluted through a glass column $(3 \times 40 \mathrm{~cm})$ filled with $60 \mathrm{~g}$ of SPFF. Prior to elution, SPFF was washed with $300 \mathrm{ml}$ of phosphate buffer (PB) (pH 6,8) containing $1 \mathrm{M} \mathrm{NaCl}$ to remove unnecessary compounds. The whey was circulated through the column using feedback tubing and a peristaltic pump. The circulation was done at the flow rate of 1.0 $\mathrm{ml} / \mathrm{min}$. After draining the whey away, the resin was washed with $300 \mathrm{ml}$ of $0.4 \mathrm{mM} \mathrm{NaCl}$ in $0.1 \mathrm{mM}$ phosphate buffer ( $\mathrm{pH}$ 7.0) using fraction collector (10 ml per tube) to obtain the solution containing high concentration of LPO. Three groups of fractions (fraction number 1$10,11-20,21-30)$ were analyzed for protein profile using sodium dodecyl sulfate polyacrylamide gel electrophoresis (SDS PAGE) to check the purity. Finally, based on the SPS PAGE analysis, the fraction number 21-30 was selected for LPO activity analysis (LPO activity was $35 \mathrm{U} / \mathrm{ml}$ ). Thus, this fraction was used throughout experiment.

\section{Determination of Captured LPO onto SP Sepharoses}

SPFF and SPBB $(0.1-1.0 \mathrm{~g})$ were washed in $1 \mathrm{M} \mathrm{NaCl}$ in PB pH 7.0 and then were placed in the column $(1 \times 10 \mathrm{~cm})$. The immobilization process was started with the elution of 1 $\mathrm{ml}$ of LPO through column. The flow rate was set into $1 \mathrm{ml} / \mathrm{min}_{\text {s }}$ using peristaltic pump. The output was collected for measurement of remained LPO activity in the SP Sepharoses. This

\section{Deleted: SP-FF}

Deleted: SP-BB

Commented [ANA11]: ABTS has been replaced as start of sentence

Commented [012]: Don't start a sentence with a numeric value. Deleted: or ABTS

Deleted: immobilization

Deleted: a

Deleted:

Deleted: group

Deleted: SDS PAGE

Deleted: analyzed

Deleted: and

\section{Deleted:}

Deleted:

Deleted: ute 
experiment was repeated three times and column were wash with serial elution of $1 \mathrm{M} \mathrm{NaOH}$ and pure water, respectively. The immobilized LPO was stored in milk, whey, pure water and whey. All storage solutions were sterilized using autoclave at $110^{\circ} \mathrm{C}$ for 10 minutes. Immobilized LPO was stored at $4^{\circ} \mathrm{C}$ for 10 days. The remaining of LPO activity immobilized onto SP-Sepharose was calculated by eluting immobilized LPO using $1 \mathrm{M} \mathrm{NaCl}$ in PB pH 7.0. The LPO activity in the elution was analyzed spectrometrically.

\section{LPO Activity Determination}

LPO activity was performed as the following method: $450 \mu 1$ of $1.0 \mathrm{mM}$ ABTS in 10 $\mathrm{mM}$ acetate buffer ( $\mathrm{pH} 4.4$ ) and $450 \mu \mathrm{l}$ of $0.55 \mathrm{mM} \mathrm{H}_{2} \mathrm{O}_{2}$ in pure water were gently poured into the cuvette. The enzyme $(50 \mu \mathrm{l})$ was subsequently added to cuvette. The increase of absorbance at $412 \mathrm{~nm}$ measured for 20 second. One unit of LPO enzymatic activity was expressed as the amount of enzyme needed to oxidize $1 \mu \mathrm{mol}$ ABTS/min. The molar extinction coefficient of ABTS at $412 \mathrm{~nm}$ was $32.400 \mathrm{M}^{-1} \mathrm{~cm}^{-1}$ (Touch et al., 2004).

\section{Immobilization Efficiency}

The immobilization efficiency (IE) was calculated as follows: $\operatorname{IE}(\%)=\mathrm{E} 1 / \mathrm{E} 0 \mathrm{x} 100$, where E0 is the LPO activity added to the SP Sepharoses $(\mathrm{U} / \mathrm{ml})$ and E1 is the LPO activity embedded in the SP Sepharose (U/ml) (Al-Baarri et al., 2010).

\section{RESULTS AND DISSCUSSION}

\section{Purification LPO}

Whey has a lot of enzymes and it is available in low cost because whey is by product of dairy manufacture so it is the challenge to use whey as enzyme sources including LPO. The LPO activity and band (s) of the solution obtained from the elution of $1 \mathrm{M} \mathrm{NaCl}$ in PB pH 7.0 through SPFF containing LPO were checked using spectrophotometer and SDS PAGE, respectively. As mention in methods, SPFF containing LPO was generated from whey that was eluted through SPFF column. The result of LPO activity was $27.7 \pm 2.9$, $39.5 \pm 4.5$, and $35.2 \pm 3.4 \mathrm{U} / \mathrm{ml}$ for fraction number $1-10,11-20,21-30$, respectively (data not presented). The highest of LPO activity was group of fraction number 11-20, however since the band of this group showed two bands indicating two protein was detected, for whole of experiment, group of fraction number 21-30 was used. This group showed single band indicating only LPO that was captured by SPFF. 
In this research SPFF was used to obtain LPO since this ion exchange resin has diameter $45-165 \mu \mathrm{m}$ resulting in the wider of surface area than SPBB (AmershamBioscience, 2001). In line with this result, Touch et al., 2004 used SPFF for purifying LPO from whey resulting in the good ability to catch LPO $\left(108 \_\mathrm{U} / \mathrm{ml}\right)$. The activity of LPO in this research was less than that of other researcher since the absence of microfiltration step in this research. It has been known that the microfiltration might concentrate the enzyme resulting in the high activity of LPO.

\section{Immobilization Efficiency}

Immobilization efficiency plays an important role for determination of immobilization agent. This research determined immobilization efficiency (IE) of LPO using SPFF dan SPBB (Figure 1). The volume of SP Sepharoses used in this experiment had a range from 0.1 to $1.0 \mathrm{~g}$ to catch the $\mathrm{LPO}$ at initial activity of $35.2 \pm 3.4 \mathrm{U} / \mathrm{ml}$. The increase of IE was found as an increase of SP Sepharoses's weight. As describe in Figure 1, when the $0.6 \mathrm{~g}$ of SPFF was employed, the IE achieved $100 \%$ indicating all of LPO employed was able to be captured by SPFF. When the weight of SPFF was increased, the IE was in steady state maximumly. An increase SPBB from 0.1 to $1.0 \mathrm{~g}$ elevated the IE from 38.6 to $100 \%$. However, $0.9 \mathrm{~g}$ of SPBB completely captured LPO resulting the IE of $100 \%$. One gram of SPFF was reported to have a maximum capture of LPO in $300 \mathrm{ml}$ whey (equal to $750 \mathrm{U} / \mathrm{ml} \mathrm{LPO}$ activity) (Al-Baarri et al., 2010). This can be explained that the capture depended on the quantity of enzymes per mililiter. This research used high activity of LPO resulting in the loss of LPO activity.

Since the SPFF and SPBB provided the maximum IE at 0.6 and $0.9 \mathrm{~g}$, respectively, thus these amounts of SP Sepharoses has been used in the rest of experiment. The LPO immobilized onto SPFF and SPBB was stored in the various storage solutions: pure water, $\mathrm{PB}$, milk, and whey for 10 days in $10^{\circ} \mathrm{C}$.

\section{Remaining LPO Activity During Storage}

The percentage of remaining immobilized LPO activity stored at $10^{\circ} \mathrm{C}$ for 10 days in various storage solutions is shown in Figure $2 \mathrm{a}$ and $2 \mathrm{~b}$. LPO activity of immobilized LPO was measured after purging the LPO attached onto SP Sepharose with $1 \mathrm{M} \mathrm{NaCl}$ in PB pH 7.0. The percentage of remaining LPO activity was determined by comparing the LPO activity after storage to the initial immobilized LPO at first day of storage.

The percentage of LPO activity attached onto SPBB and SPFF is shown on Figure 2a and Figure 2b, respectively. Based on Figure 2a, whey was able to maintain $100 \%$ enzyme
Deleted: Figure 1 shows w

Deleted: might be

Deleted: these amount

Deleted: $\mathrm{p}$

Commented [014]: Author has cited Figure 3 in text but didn't provide it in the submitted manuscript. Provide this missing figure and make sure that all figures have been cited in text in consecutive numerical order. All cited figures must be presented in the manuscript and all presented figures must be cited in the text at appropriate places along with their suitable explanation.

Commented [015]: Provide correct reference of all figures in text.

Commented [ANA16]: I have double checked about this.

Deleted: 2

Deleted: LPO 
activity of LPO attached onto SPBB within 4 days. The extention of storage time resulted in the remarkable reduction of remaining LPO activity. Milk was able to maintain the LPO activity at seven days of storage even though the remaining of LPO activity at that time was very negligible in amount $(2.3 \%)$.

As previously mentioned, whey was able to completely keep LPO activity within 4 days of storage. This can be explained that whey components support the activity of LPO. It has been studied that LPO activity might be inhibited by casein (Singh et al., 2009) while the casein has been removed from whey.

The remaining of LPO activity attached onto SPFF during 10 days of storage at $10^{\circ} \mathrm{C}$ is shown on Figure $2 \mathrm{~b}$. PB was able to maintain $100 \%$ of LPO activity within 5 days of storage. The milk and whey were able to keep $100 \%$ of LPO activity within 3 days of storage. The elevation of storage time until 5 days in whey could keep enzyme activity although the remaining enzyme activity was small amount (10.08\%). Based on the availability, also since LPO was simply derived from whey, the storage of immobilized LPO in whey should keep its activity up to 5 days of storage. Therefore it is suggested that immobilized LPO should be stored in whey.

\section{CONCLUSION}

The results can be concluded that LPO could be purified from whey using fraction number 21-30. One mililiter of LPO (35 U/ml) could be completely immobilized onto $0.6 \mathrm{~g}$ SPFF or $0.9 \mathrm{~g}$ SPBB (immobilization efficiency was 100\%). Among various storage solution, whey was able to keep $100 \%$ of LPO activity up to 5 days of storage.

\section{ACKNOWLEDGMENT}

This work was supported by funds from the Ministry of Research and Technology of

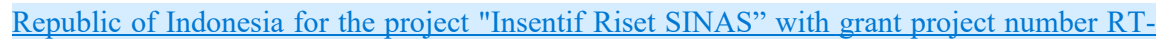
2013-2163.

\section{REFERENCES}

Al-Baarri, A.N., M. Hayashi, M. Ogawa and S. Hayakawa, 2011a. Effects of mono- and disaccharides on the antimicrobial activity of bovine lactoperoxidase system. J. Food Prot., 74: 134-139.

\section{$1174452 j a$}

Commented [ANA17]: I have double check for the explanation of figure and proper figure

Deleted:

Formatted: Indent: First line: $0 \mathrm{~cm}$

Formatted: Level 1, Indent: First line: $0 \mathrm{~cm}$

Formatted: Indent: First line: $0 \mathrm{~cm}$

Commented [ANA18]: Please allow us to explain the our acknoledgment

Formatted: Level 1, Indent: First line: $0 \mathrm{~cm}$

Deleted: Al-Baarri, A.N., 2011. Lactoperoxidase Activity o Bovine Whey at Critical Temperature Storage. Unplublished data. 
Al-Baarri, A.N., M. Ogawa and S. Hayakawa, 2010. Scale-up studies on immobilization of lactoperoxidase using milk whey for producing antimicrobial agent. J. Indonesian Trop. Anim. Agric., 35: 185-191.

\section{$1174454 j a$}

Al-Baarri, A.N., M. Ogawa and S. Hayakawa, 2011b. Application of lactoperoxidase system using bovine whey and the effect of storage condition on lactoperoxidase activity. Int. J. Dairy Sci., 6: 72-78.

\section{0ja}

Al-Baarri, A.N., M. Ogawa, T. Visalsok and S. Hayakawa, 2012. Lactoperoxidase immobilized onto various beads for producing natural preservatives solution. J. Applied Food Technol., 1: 4-6.

\section{$1174455 j a$}

Amersham-Bioscience, 2001. Use of sodium hydroxide for cleaning and sanitizing chromatography media and systems. Application Note 18-1124-57 AD, Process Chromatography, Amersham Bioscience, USA.

\section{$62223 a n$}

Oghaiki, N.A., F. Fonteh, P. Kamga, S. Mendi and H. Imele, 2007. Activation of the lsctoperoxidise system as a method of preserving raw milk in areas without cooling facilities. Afr. J. Food Agric. Nutr. Dev., 7: 1-14.

\section{9ja}

Boots, J.W. and R. Floris, 2006. Lactoperoxidase: From catalytic mechanism to practical applications. Int. Dairy J., 16: 1272-1276.

\section{2ja}

FAO/WHO, 2005. Benefits and potential risks of the lactoperoxidase system of raw milk preservation. Report of an FAO/WHO Technical Meeting, November 28-December 2, 2005, FAO Headquarters, Rome, Italy, pp: 1-73.

\section{3an}

C.J. and A. Chand, 2006. Capture of lactoferrin and lactoperoxidase from raw whole milk by cation exchange chromatography. Separation Purification Technol., 48, 143-149.

\section{1ja}

Fweja, L.W.T., M.J. Lewis and A.S. Grandison, 2008. Challenge testing the lactoperoxidase system against a range of bacteria using different activation agents. J. Dairy Sci., 91: $2566-2574$ 


\section{2ja}

Hayashi, M., S. Naknukool, S. Hayakawa, M. Ogawa and A.B.A. Ni'matulah, 2012.

Enhancement of antimicrobial activity of a lactoperoxidase system by carrot extract and $\beta$-carotene. Food Chem., 130: 541-546.

\section{9ja}

Seifu, E., E.M. Buys and E.F. Donkin, 2004. Quality aspects of Gouda cheese made from goat milk preserved by the lactoperoxidase system. Int. Dairy J., 14: 581-589.

\section{$1181348 j a$}

Seifu, E., E.M. Buys and E.F. Donkin, 2005. Significance of the lactoperoxidase system in the dairy industry and its potential applications: A review. Trends Food Sci. Technol., 16: 137-154.

\section{$571875 j a$}

Singh, A.K., N. Singh, S. Sharma, K. Shin and M. Takase et al., 2009. Inhibition of lactoperoxidase by its own catalytic product: Crystal structure of the hypothiocyanateinhibited bovine lactoperoxidase at 2.3-A resolution. Biophys. J., 96: 646-654.

\section{$568418 j a$}

Touch, V., S. Hayakawa, S. Yamada and S. Kaneko, 2004. Effects of a lactoperoxidasethiocyanate-hydrogen peroxide system on $<\mathrm{i}>$ Salmonella enteritidis $</ \mathrm{i}>$ in animal or vegetable foods. Int. J. Food Microbiol., 93: 175-183.

\section{$78030 \mathrm{ja}$}

Zhou, Y. and L.T. Lim, 2009. Activation of lactoperoxidase system in milk by glucose oxidase immobilized in electrospun polylactide microfibers. J. Food Sci., 74: C170-C176.

$568445 j a$

\section{Shahzaib 28-8-2013, \{Add by saira: 28-08-13\}}


Figure 1. Immobilization efficiency (IE) of LPO on two types of resin, i.e. SP Sepharose BigBeads (SPBB) and SP Sepharose Fast Flow (SPFF). Two types of resin $(0.1-1.0 \mathrm{~g})$ was used to immobilized $1 \mathrm{ml}$ of LPO $(35 \mathrm{U} / \mathrm{ml})$. Flow rate has been set to $1 \mathrm{ml} / \mathrm{min}$ using peristaltic pump. Values are means of three sets of experiments. Error bars represent standard errors of the mean.

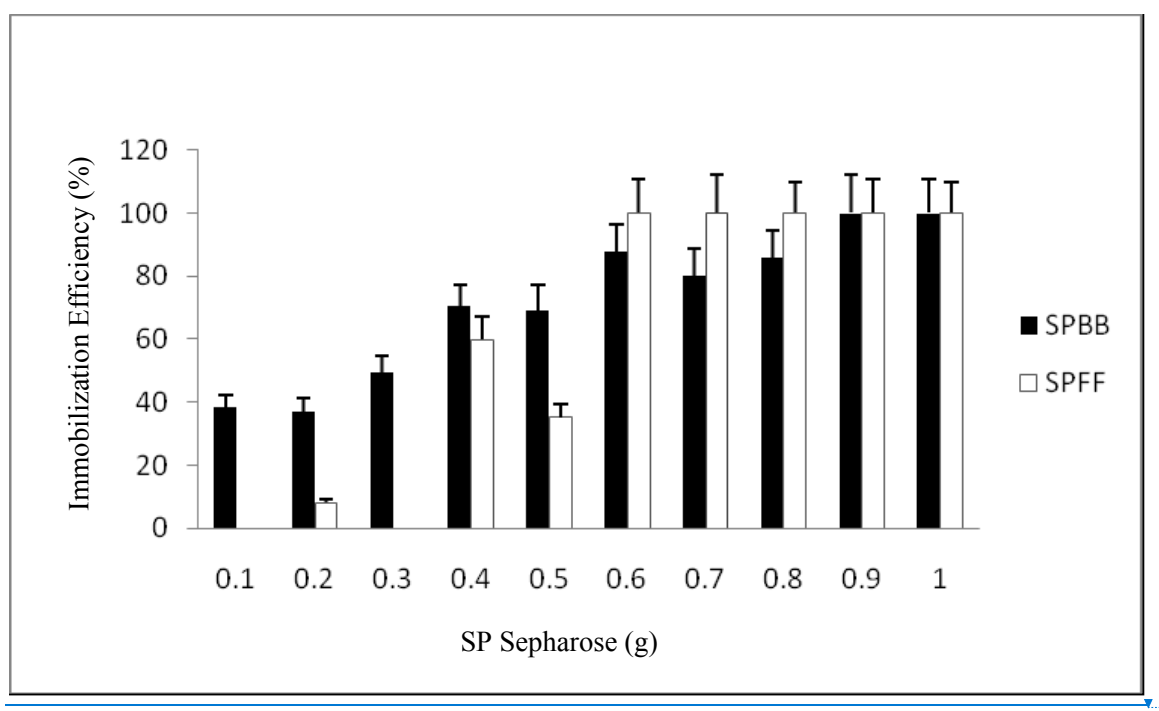

Commented [ANA21]: Table 1 has been deleted and the content has been explained in the text.

Commented [022]: Define all abbreviations used in figures in their respective captions.

Commented [023]: The given captions of your figures 1 and 2 have not been written properly. A figure should be self-explanatory and its caption plays a very important role in this regard. Provide such captions for all these figures in which all of their main parts have been properly explained.

Formatted: Indent: Left: $0 \mathrm{~cm}$, First line: $0 \mathrm{~cm}$

Deleted: ?

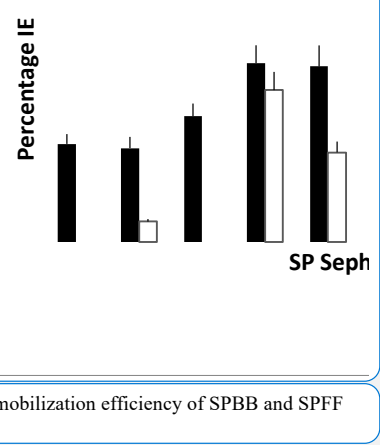

Deleted: Figure 1. Immobilization efficiency of SPBB and SPFF Deleted: Figure 1 .
using various weight. 
Figure 2a. The percentage of remaining LPO activity attached onto SP Sepharose Big Beads (SPBB) during 10 days of storage at $10^{\circ} \mathrm{C}$ in various storage solutions. This experiment used $1 \mathrm{~g}$ of SPBB for immobilizing $1 \mathrm{ml}$ of LPO (35 U/ml). Immediately after immobilization, SPBB then was stored in sterilized pure water, phosphate buffer, milk, and whey for 10 days at $10^{\circ} \mathrm{C}$. Values are mean of three sets of experiments. Error bars represent standard errors of the mean

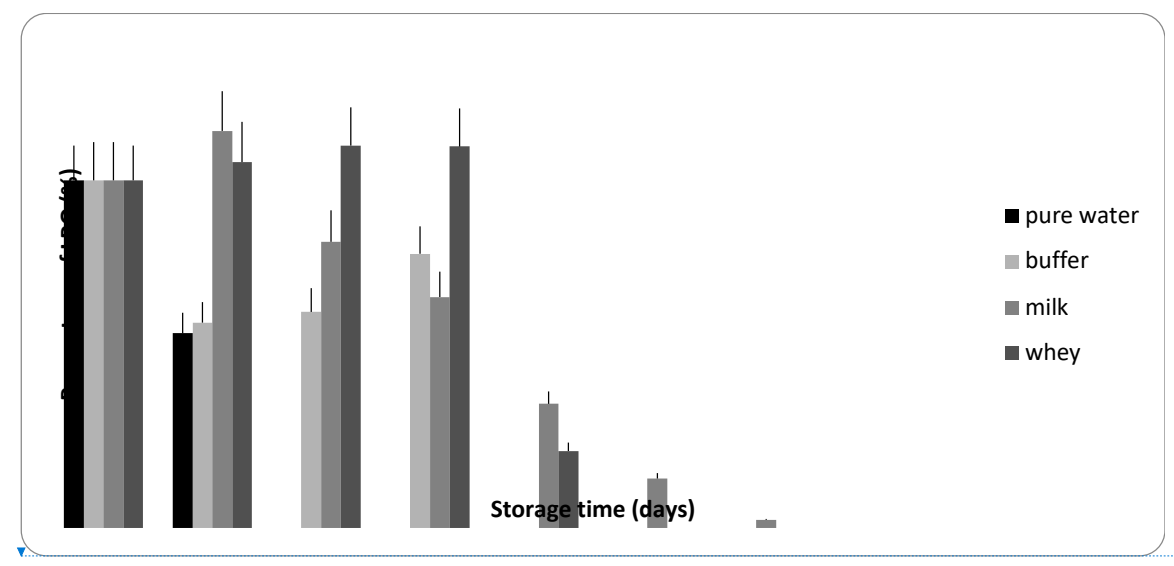

Figure $2 \mathrm{~b}$ The percentage of remaining LPO activity attached onto SP Sepharose Fast Flow (SPFF) during 10 days of storage at $10^{\circ} \mathrm{C}$ in various storage solution. This experiment used $1 \mathrm{~g}$ of SPFF for immobilizing $1 \mathrm{ml}$ of LPO $(35 \mathrm{U} / \mathrm{ml})$. After immobilization, SPFF was stored in sterilized pure water, phosphate buffer, milk, and whey. Values are mean of three sets of experiments. Error bars represent $\underline{\text { standard errors of the mean }}$

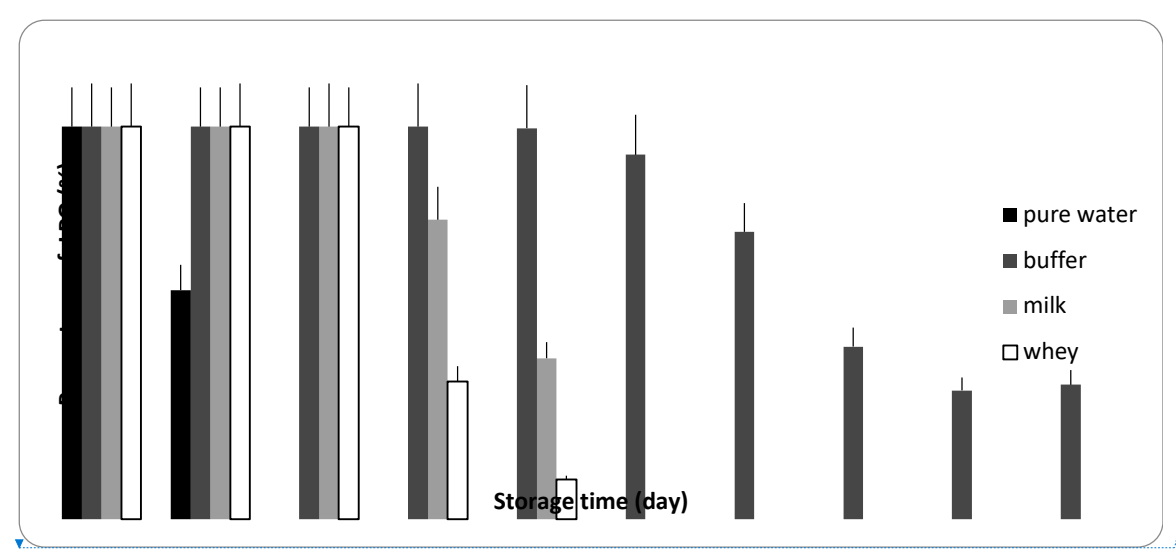

Formatted: Indent: Left: $0 \mathrm{~cm}$, First line: $0 \mathrm{~cm}$

Deleted:

Commented [FT26]: Assign an alphabet to each sub-part of Figure 2 and explain each figure part in figure caption by referring to its respective alphabet. A figure should be self-explanatory and its caption plays a very important role in this regard. Provide such caption in which all main parts of this figure have been properly explained. All cited figures must be presented in the manuscript and all presented figures must be cited in the text at appropriate places along with their suitable explanation.

Commented [027]: In submitted manuscript Figure 2 has been presented but Author didn't cite this figure in text. Cite this figure in text at appropriate place with suitable explanation and make sure that all figures have been cited in text in consecutive numerical order. All cited figures must be presented in the manuscript and all presented figures must be cited in the text at appropriate places along with their suitable explanation.

Commented [ANA28]: Self explanatory has been added

Commented [ANA29]: This figure has been presented in the article.

Deleted: Figure 2a. The percentage of LPO activity attached onto SPBB during ten days of storage in various storage solutions? 
Deleted: Figure $2 \mathrm{~b}$ The percentage of LPO activity attached onto

SPFF during ten days of storage in various storage solution. ๆ 
Journal Name

ISSN

Copy Right

\title{
Resistance of Immobilized Lactoperoxidase Activity from Bovine Whey Against Storage Solutions
}

\author{
${ }^{1}$ Dwi Novrina Nawangsari, ${ }^{2}$ Ahmad Ni'matullah Al-Baarri, ${ }^{2}$ Sri Mulyani, \\ ${ }^{2}$ Anang Mohamad Legowo and ${ }^{2}$ V. Priyo Bintoro \\ ${ }^{1}$ Department of Animal Product Technology, \\ ${ }^{2}$ Department of Food Technology, Faculty of Animal and Agricultural Sciences, Diponegoro University, \\ Semarang, Indonesia
}

Corresponding Author: Ahmad Ni'matullah Al-Baari, Department of food Technology, Faculty of Animal and Agricultural Sciences, Diponegoro University, Semarang, Indonesia

\begin{abstract}
Lactoperoxidase (LPO) could be simply obtained from whey through immobilization using a cation exchange resin of SP Sepharose. LPO received high attention since the antimicrobial properties of LPO system (LPOS) that are consisted of $\mathrm{LPO}, \mathrm{SCN}^{-}$and $\mathrm{H}_{2} \mathrm{O}_{2}$ was able to generate $\mathrm{OSCN}^{-}$for strong antimicrobial agents. This study was done to analyze the immobilization efficiency of LPO onto two types of sepharose: SP-Sepharose Fast Flow (SPFF) and SP-Sepharose Big Beads (SPBB). The remaining of LPO's activity (\%) against storage solution was also observed. The whey was obtained from bovine skimmed milk that was coagulated using rennet and acid lactic. The LPO was obtained from whey using SPFF. To analyze the resistence of enzyme activity, the immobilized LPO was stored in pure water, phosphate buffer, milk and whey at $10^{\circ} \mathrm{C}$. The activity of LPO was monitored for 10 days. The result indicates that the LPO could be purified from whey and single band has been detected using electrophoresis method. The obtained LPO (35 $\mathrm{U} \mathrm{mL}^{-1}$ ) was attached onto SPFF and SPBB. Maximum immobilization efficiency has been achieved by $0.6 \mathrm{~g}$ SP-FF and $0.9 \mathrm{~g}$ SP-BB. LPO activity of the immobilized LPO were able to be kept until 5 days when it was stored in whey. Other storage solution remained various LPO activity during storage. This study concluded that IE of LPO attached onto sepharoses might be reached variously depended on the sepharose type and whey as LPO source might be used for maintaining LPO activity.
\end{abstract}

Key words: Lactoperoxidase, SP sepharose fast flow, SP sepharose big beads, immobilization, remaining activity

\section{INTRODUCTION}

Lactoperoxidase (LPO), together with $\mathrm{SCN}^{-}$and $\mathrm{H}_{2} \mathrm{O}_{2}$ have been understood to generates intermediate product of $\mathrm{OSCN}^{-}$as antibacterial agent that has a broad spectrum of antimicrobial effects against bacteria, fungi and viruses. This antibacterial agent could be produced if these three components exist in the medium (Seifu et al., 2005). LPOS has been widely used as a preservative in dairy products and nondairy products (Seifu et al., 2004; Touch et al., 2004; FAO/WHO, 2005; Boots and Floris, 2006; Oghaiki et al., 2007; Fweja et al., 2008; Al-Baarri et al., 2011a).

It has been understood that whey contains large number of LPO therefore purification method of LPO from whey has been well developed (Touch et al., 2004; Zhou and Lim, 2009; 


\section{J. Name}

Al-Baarri et al., 2010). SP-Sepharose has been known to provide beneficial effect for the immobilization efficiency since SP-Sepharose almost completely immobilized LPO and reusable (Al-Baarri et al., 2010). Although, LPOS was widely used in food application but it still remained the problem of its expensiveness, therefore the immobilization of LPO was needed for the reuse of LPO.

SP Sepharose has been known as immobilization agent for capturing lactoperoxidase (Fee and Chand, 2006; Hayashi et al., 2012). SP Sepharose Fast Flow (SPFF) and SP Sepharose Big Beads (SPBB) were the common resin for immobilization since the they provide simply application, long term of use and easy for reuse (Amersham-Bioscience, 2001). If compare to other immobilization agent such as chitosan, SP Sepharoses showed higher capturization of lactoperoxidase (Al-Baarri et al., 2012). In the other hand, SP Sepharose application for immobilization of LPO resulting in the much more expensive of the use of LPO, therefore the efficient use of SP Sepharose to immobilize LPO is required. Based on related literatures, there was no documentation for the efficient use of LPO immobilization using SP Sepharose, therefore this research has been done for analyzing the maximum capturization of LPO onto SP Sepharose. This information might provide the benefit for minimum use of SP Sepharose for LPO immobilization. Since the immobilized LPO allowed the reuse of enzyme, the appropriate storage solution for keeping the enzyme activity is needed. To answer this, this research has also been done for analyzing the remaining of LPO activity after storage.

\section{MATERIALS AND METHODS}

Materials: SP Sepharose Fast Flow and SP Sepharose Big Beads were purchased from Amersham Pharmacia Biotech, Sweden (Lot. No. 10029743 and 10081054, respectively). Microbial derived rennet was purchased from Singapore and ABTS or 2,20-azino-bis (3-ethylbenz-thiazoline-6sulphonic acid) was obtained from Kagawa Science (Lot No. 7ROZC-EC) Tokyo Chemical, Industry Co. Ltd., Japan. Cow's milk was obtained from Faculty of Animal and Agricultural Sciences's farm, Diponegoro University, Semarang, Indonesia. The spectrophotometer (Mini UV-1800, Schimadzu, Japan) was used for analysis enzyme activity. Unless other compounds specified, all other compounds were reagent grade.

Preparation of whey: The whey was prepared as method performed by Al-Baarri et al. (2011b) without any modification.

LPO immobilization from whey: The procedure for immobilization of LPO was conducted as the method that was performed by Al-Baarri et al. (2010) with minor modifications. SP Sepharose Fast Flow (SPFF) was used as agent for LPO immobilization from whey. Whey at the volume of $1800 \mathrm{~mL}$ was eluted through a glass column $(3 \times 40 \mathrm{~cm})$ filled with $60 \mathrm{~g}$ of SPFF. Prior to elution, $\mathrm{SPFF}$ was washed with $300 \mathrm{~mL}$ of Phosphate Buffer (PB) (pH 6.8) containing $1 \mathrm{M} \mathrm{NaCl}$ to remove unnecessary compounds. The whey was circulated through the column using feedback tubing and a peristaltic pump. The circulation was done at the flow rate of $1.0 \mathrm{~mL} \mathrm{~min}{ }^{-1}$. After draining the whey away, the resin was washed with $300 \mathrm{~mL}$ of $0.4 \mathrm{mM} \mathrm{NaCl}$ in $0.1 \mathrm{mM}$ phosphate buffer $(\mathrm{pH} 7.0)$ using fraction collector $(10 \mathrm{~mL}$ per tube) to obtain the solution containing high concentration of LPO. Three groups of fractions (fraction number 1-10, 11-20, 21-30) were analyzed for protein profile using sodium dodecyl sulfate polyacrylamide gel electrophoresis 


\section{J. Name}

(SDS-PAGE) to check the purity. Finally, based on the SPS PAGE analysis, the fraction number 21-30 was selected for LPO activity analysis (LPO activity was $35 \mathrm{U} \mathrm{mL}^{-1}$ ). Thus, this fraction was used throughout experiment.

Determination of captured LPO onto SP sepharoses: SPFF and SPBB (0.1-1.0 g) were washed in $1 \mathrm{M} \mathrm{NaCl}$ in $\mathrm{PB} \mathrm{pH} 7.0$ and then were placed in the column $(1 \times 10 \mathrm{~cm})$. The immobilization process was started with the elution of $1 \mathrm{~mL}$ of LPO through column. The flow rate was set into $1 \mathrm{~mL} \mathrm{~min}{ }^{-1}$ using peristaltic pump. The output was collected for measurement of remained LPO activity in the SP Sepharoses. This experiment was repeated three times and column were wash with serial elution of $1 \mathrm{M} \mathrm{NaOH}$ and pure water, respectively. The immobilized LPO was stored in pure water, $\mathrm{PB}$, milk and whey. All storage solutions were sterilized using autoclave at $110^{\circ} \mathrm{C}$ for $10 \mathrm{~min}$. Immobilized LPO was stored at $4^{\circ} \mathrm{C}$ for 10 days. The remaining of LPO activity immobilized onto SP-Sepharose was calculated by eluting immobilized LPO using $1 \mathrm{M} \mathrm{NaCl}$ in PB $\mathrm{pH}$ 7.0. The LPO activity in the elution was analyzed spectrometrically.

LPO activity determination: $\mathrm{LPO}$ activity was performed as the following method: $450 \mu \mathrm{L}$ of $1.0 \mathrm{mM}$ ABTS in $10 \mathrm{mM}$ acetate buffer $(\mathrm{pH} 4.4)$ and $450 \mu \mathrm{L}$ of $0.55 \mathrm{mM} \mathrm{H}_{2} \mathrm{O}_{2}$ in pure water were gently poured into the cuvette. The enzyme $(50 \mu \mathrm{L})$ was subsequently added to cuvette. The increase of absorbance at $412 \mathrm{~nm}$ measured for $20 \mathrm{sec}$. One unit of LPO enzymatic activity was expressed as the amount of enzyme needed to oxidize $1 \mu \mathrm{mol}$ ABTS $\mathrm{min}^{-1}$. The molar extinction coefficient of ABTS at $412 \mathrm{~nm}$ was $32.400 \mathrm{M}^{-1} \mathrm{~cm}^{-1}$ (Touch et al., 2004).

Immobilization efficiency: The immobilization efficiency (IE) was calculated as follows:

$$
\operatorname{IE}(\%)=\frac{E_{1}}{E_{0}} \times 100
$$

where, $\mathrm{E}_{0}$ is the LPO activity added to the SP Sepharoses $\left(\mathrm{U} \mathrm{mL}^{-1}\right)$ and $\mathrm{E}_{1}$ is the LPO activity embedded in the SP Sepharose ( $\mathrm{U} \mathrm{mL}^{-1}$ ) (Al-Baarri et al., 2010).

\section{RESULTS AND DISCUSSION}

Purification LPO: Whey has a lot of enzymes and it is available in low cost because whey is by product of dairy manufacture so it is the challenge to use whey as enzyme sources including LPO. The LPO activity and band(s) of the solution obtained from the elution of $1 \mathrm{M} \mathrm{NaCl}$ in PB pH 7.0 through SPFF containing LPO were checked using spectrophotometer and SDS PAGE, respectively. As mention in methods, SPFF containing LPO was generated from whey that was eluted through SPFF column. The result of LPO activity was $27.7 \pm 2.9,39.5 \pm 4.5$ and $35.2 \pm 3.4 \mathrm{U} \mathrm{mL}^{-1}$ for fraction number 1-10, 11-20, 21-30, respectively (data not presented). The highest of LPO activity was group of fraction number 11-20, however since the band of this group showed two bands indicating two protein was detected, for whole of experiment, group of fraction number 21-30 was used. This group showed single band indicating only LPO that was captured by SPFF.

In this research SPFF was used to obtain LPO since this ion exchange resin has diameter 45-165 $\mu \mathrm{m}$ resulting in the wider of surface area than SPBB (Amersham-Bioscience, 2001). In line with this result, Touch et al. (2004) used SPFF for purifying LPO from whey resulting in the good 


\section{J. Name}

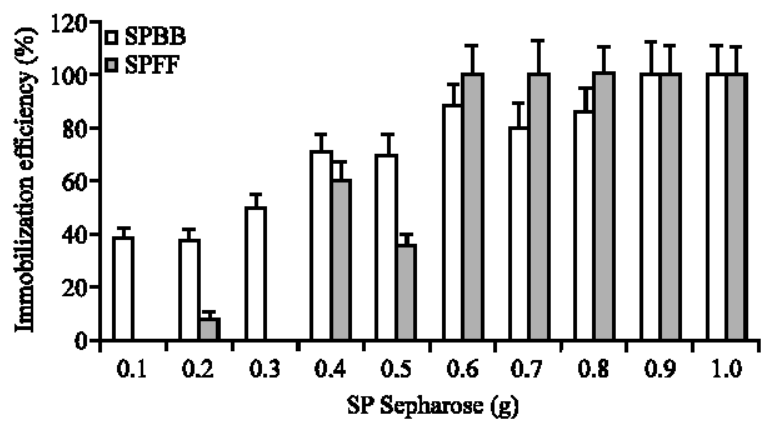

Fig. 1: Immobilization efficiency (IE) of LPO on two types of resin, i.e., SP Sepharose Big Beads (SPBB) and SP Sepharose Fast Flow (SPFF). Two types of resin (0.1-1.0 g) was used to immobilized $1 \mathrm{~mL}$ of LPO (35 $\left.\mathrm{U} \mathrm{mL}^{-1}\right)$. Flow rate has been set to $1 \mathrm{~mL} \mathrm{~min}^{-}$tusing peristaltic pump. Values are means of three sets of experiments, Error bars represent standard errors of the mean

ability to catch LPO (108 $\left.\mathrm{U} \mathrm{mL}^{-1}\right)$. The activity of LPO in this research was less than that of other researcher since the absence of microfiltration step in this research. It has been known that the microfiltration might concentrate the enzyme resulting in the high activity of LPO.

Immobilization efficiency: Immobilization efficiency plays an important role for determination of immobilization agent. This research determined Immobilization Efficiency (IE) of LPO using SPFF dan SPBB (Fig. 1). The volume of SP Sepharoses used in this experiment had a range from 0.1 to $1.0 \mathrm{~g}$ to catch the $\mathrm{LPO}$ at initial activity of $35.2 \pm 3.4 \mathrm{U} \mathrm{mL}^{-1}$. The increase of IE was found as an increase of SP Sepharoses's weight. As describe in Fig. 1, when the $0.6 \mathrm{~g}$ of SPFF was employed, the IE achieved 100\% indicating all of LPO employed was able to be captured by SPFF. When the weight of SPFF was increased, the IE was in steady state maximumly. An increase SPBB from 0.1 to $1.0 \mathrm{~g}$ elevated the IE from 38.6 to $100 \%$. However, $0.9 \mathrm{~g}$ of SPBB completely captured $\mathrm{LPO}$ resulting the $\mathrm{IE}$ of $100 \%$. One gram of SPFF was reported to have a maximum capture of LPO in $300 \mathrm{~mL}$ whey (equal to $750 \mathrm{U} \mathrm{mL}^{-1} \mathrm{LPO}$ activity) (Al-Baarri et al., 2010). This can be explained that the capture depended on the quantity of enzymes per mililiter. This research used high activity of LPO resulting in the loss of LPO activity.

Since the SPFF and SPBB provided the maximum IE at 0.6 and $0.9 \mathrm{~g}$, respectively, thus these amounts of SP Sepharoses has been used in the rest of experiment. The LPO immobilized onto $\mathrm{SPFF}$ and $\mathrm{SPBB}$ was stored in the various storage solutions: Pure water, $\mathrm{PB}$, milk and whey for 10 days at $10^{\circ} \mathrm{C}$.

Remaining LPO activity during storage: The percentage of remaining immobilized LPO activity stored at $10^{\circ} \mathrm{C}$ for 10 days in various storage solutions is shown in Fig. 2a and b. LPO activity of immobilized LPO was measured after purging the LPO attached onto SP Sepharose with $1 \mathrm{M} \mathrm{NaCl}$ in $\mathrm{PB} \mathrm{pH} \mathrm{7.0.} \mathrm{The} \mathrm{percentage} \mathrm{of} \mathrm{remaining} \mathrm{LPO} \mathrm{activity} \mathrm{was} \mathrm{determined} \mathrm{by} \mathrm{comparing}$ the LPO activity after storage to the initial immobilized LPO at first day of storage.

The percentage of LPO activity attached onto SPBB and SPFF is shown on Fig. 2a and b, respectively. Based on Fig. 2a, whey was able to maintain 100\% enzyme activity of LPO attached onto SPBB within 4 days. The extention of storage time resulted in the remarkable 


\section{J. Name}
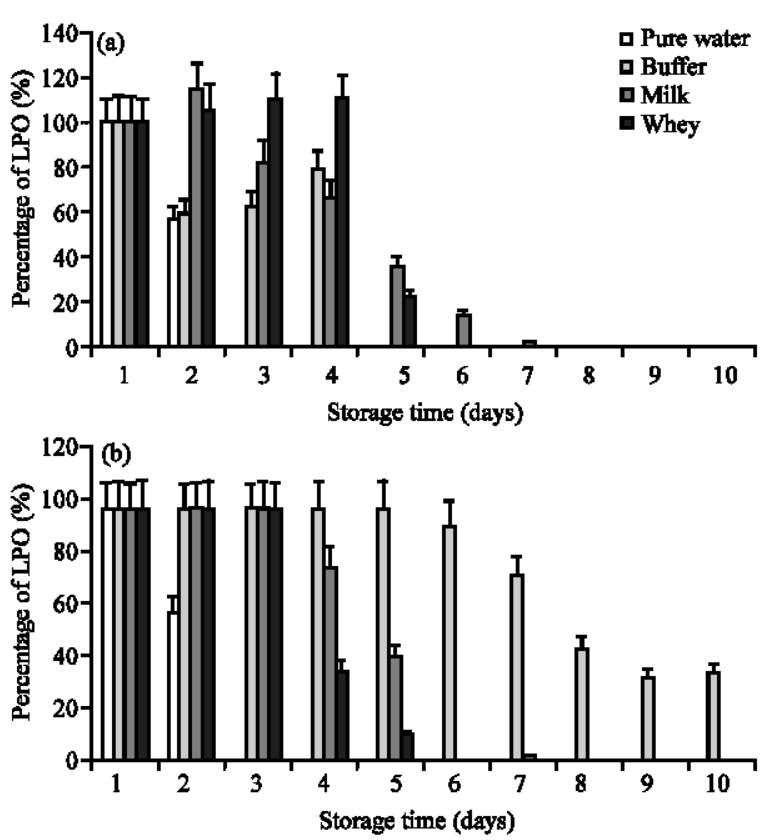

Fig. 2(a-b): (a) Percentage of remaining LPO activity attached onto SP Sepharose Big Beads (SPBB) during 10 days of storage at $10^{\circ} \mathrm{C}$ in various storage solutions. This experiment used $1 \mathrm{~g}$ of SPBB for immobilizing $1 \mathrm{~mL}$ of LPO $\left(35 \mathrm{U} \mathrm{mL}^{-1}\right)$. Immediately after immobilization, SPBB then was stored in sterilized pure water, phosphate buffer, milk and whey for 10 days at $10^{\circ} \mathrm{C}$. Values are mean of three sets of experiments. Error bars represent standard errors of the mean and (b) Percentage of remaining LPO activity attached onto SP Sepharose Fast Flow (SPFF) during 10 days of storage at $10^{\circ} \mathrm{C}$ in various storage solution. This experiment used $1 \mathrm{~g}$ of SPFF for immobilizing $1 \mathrm{~mL}$ of LPO (35 $\left.\mathrm{U} \mathrm{mL}^{-1}\right)$. After immobilization, SPFF was stored in sterilized pure water, phosphate buffer, milk and whey. Values are mean of three sets of experiments. Error bars represent standard errors of the mean

reduction of remaining LPO activity. Milk was able to maintain the LPO activity at seven days of storage even though the remaining of LPO activity at that time was very negligible in amount $(2.3 \%)$.

As previously mentioned, whey was able to completely keep LPO activity within 4 days of storage. This can be explained that whey components support the activity of LPO. It has been studied that LPO activity might be inhibited by casein (Singh et al., 2009) while the casein has been removed from whey.

The remaining of LPO activity attached onto SPFF during 10 days of storage at $10^{\circ} \mathrm{C}$ is shown on Fig. 2b. PB was able to maintain $100 \%$ of LPO activity within 5 days of storage. The milk and whey were able to keep 100\% of LPO activity within 3 days of storage. The elevation of storage time until 5 days in whey could keep enzyme activity although the remaining enzyme activity was small amount $(10.08 \%)$. Based on the availability, also since LPO was simply derived from whey, the storage of immobilized LPO in whey should keep its activity up to 5 days of storage. Therefore it is suggested that immobilized LPO should be stored in whey. 


\section{J. Name}

\section{CONCLUSION}

The results can be concluded that LPO could be purified from whey using fraction number 21-30. One mililiter of LPO (35 $\mathrm{U} \mathrm{mL}^{-1}$ ) could be completely immobilized onto $0.6 \mathrm{~g} \mathrm{SPFF}$ or $0.9 \mathrm{~g}$ SPBB (immobilization efficiency was $100 \%$ ). Among various storage solution, whey was able to keep $100 \%$ of LPO activity up to 5 days of storage.

\section{ACKNOWLEDGMENTS}

This study was supported by funds from the Ministry of Research and Technology of Republic of Indonesia for the project "Insentif Riset SINAS" with Grant Project No. RT-2013-2163.

\section{REFERENCES}

Al-Baarri, A.N., M. Ogawa and S. Hayakawa, 2010. Scale-up studies on immobilization of lactoperoxidase using milk whey for producing antimicrobial agent. J. Indonesian Trop. Anim. Agric., 35: 185-191.

Al-Baarri, A.N., M. Hayashi, M. Ogawa and S. Hayakawa, 2011a. Effects of mono-and disaccharides on the antimicrobial activity of bovine lactoperoxidase system. J. Food Prot., 74: 134-139.

Al-Baarri, A.N., M. Ogawa and S. Hayakawa, 2011b. Application of lactoperoxidase system using bovine whey and the effect of storage condition on lactoperoxidase activity. Int. J. Dairy Sci., 6: $72-78$.

Al-Baarri, A.N., M. Ogawa, T. Visalsok and S. Hayakawa, 2012. Lactoperoxidase immobilized onto various beads for producing natural preservatives solution. J. Applied Food Technol., 1: 4-6.

Amersham-Bioscience, 2001. Use of sodium hydroxide for cleaning and sanitizing chromatography media and systems. Application Note 18-1124-57 AD, Process Chromatography, Amersham Bioscience, USA. http://risk.management6.com/Use-of-sodium-hydroxide-for-cleaning-andsanitizing-chromatography-download-w15138.pdf.

Boots, J.W. and R. Floris, 2006. Lactoperoxidase: From catalytic mechanism to practical applications. Int. Dairy J., 16: 1272-1276.

FAO/WHO, 2005. Benefits and potential risks of the lactoperoxidase system of raw milk preservation. Report of an FAO/WHO Technical Meeting, November 28-December 2, 2005, FAO Headquarters, Rome, Italy, pp: 1-73.

Fee, C.J. and A. Chand, 2006. Capture of lactoferrin and lactoperoxidase from raw whole milk by cation exchange chromatography. Separation Purification Technol., 48: 143-149.

Fweja, L.W.T., M.J. Lewis and A.S. Grandison, 2008. Challenge testing the lactoperoxidase system against a range of bacteria using different activation agents. J. Dairy Sci., 91: $2566-2574$.

Hayashi, M., S. Naknukool, S. Hayakawa, M. Ogawa and A.B.A. Ni'matulah, 2012. Enhancement of antimicrobial activity of a lactoperoxidase system by carrot extract and $\alpha$-carotene. Food Chem., 130: 541-546.

Oghaiki, N.A., F. Fonteh, P. Kamga, S. Mendi and H. Imele, 2007. Activation of the lsctoperoxidise system as a method of preserving raw milk in areas without cooling facilities. Afr. J. Food Agric. Nutr. Dev., 7: 1-14.

Seifu, E., E.M. Buys and E.F. Donkin, 2004. Quality aspects of Gouda cheese made from goat milk preserved by the lactoperoxidase system. Int. Dairy J., 14: 581-589. 


\section{J. Name}

Seifu, E., E.M. Buys and E.F. Donkin, 2005. Significance of the lactoperoxidase system in the dairy industry and its potential applications: A review. Trends Food Sci. Technol., 16: 137-154.

Singh, A.K., N. Singh, S. Sharma, K. Shin and M. Takase et al., 2009. Inhibition of lactoperoxidase by its own catalytic product: Crystal structure of the hypothiocyanate-inhibited bovine lactoperoxidase at 2.3-A resolution. Biophys. J., 96: 646-654.

Touch, V., S. Hayakawa, S. Yamada and S. Kaneko, 2004. Effects of a lactoperoxidase-thiocyanatehydrogen peroxide system on Salmonella enteritidis in animal or vegetable foods. Int. J. Food Microbiol., 93: 175-183.

Zhou, Y. and L.T. Lim, 2009. Activation of lactoperoxidase system in milk by glucose oxidase immobilized in electrospun polylactide microfibers. J. Food Sci., 74: C170-C176. 
J. Name

ISSN

Copy Right

\title{
Resistance of Immobilized Lactoperoxidase Activity from Bovine Whey Against Storage Solutions
}

\author{
${ }^{1}$ Dwi Novrina Nawangsari, ${ }^{2}$ Ahmad Ni'matullah Al-Baarri, ${ }^{2}$ Sri Mulyani, \\ ${ }^{2}$ Anang Mohamad Legowo and ${ }^{2}$ V. Priyo Bintoro The complete address for author 1: Department of Animal Science, Faculty of \\ ${ }^{1}$ Department of Animal Product Technology, \\ Animal and Agricultural Sciences, \\ Diponegoro University, Semarang, Indonesia \\ ${ }^{2}$ Department of Food Technology, Faculty of Animal and Agricultural Sciences, Diponegoro University, \\ Semarang, Indonesia \\ Corresponding author should be addressed to: Ahmad Ni'matullah Al-Baarri, Department of Food Technology, Faculty of Animal and Agricultural Sciences, \\ Diponegoro University, Semarang, Indonesia (albari@undip.ac.id) \\ Corresponding Author: Dwi Novrina Nawangsari, Department of Animal Product Technology, Faculty of Animal and \\ Agricultural Sciences, Diponegoro University, Semarang, Indonesia
}

\begin{abstract}
Lactoperoxidase (LPO) could be simply obtained from whey through immobilization using a cation exchange resin of SP Sepharose. LPO received high attention since the antimicrobial properties of LPO system (LPOS) that are consisted of $\mathrm{LPO}, \mathrm{SCN}^{-}$and $\mathrm{H}_{2} \mathrm{O}_{2}$ was able to generate $\mathrm{OSCN}^{-}$for strong antimicrobial agents. This study was done to analyze the immobilization efficiency of LPO onto two types of sepharose: SP-Sepharose Fast Flow (SPFF) and SP-Sepharose Big Beads (SPBB). The remaining of LPO's activity (\%) against storage solution was also observed. The whey was obtained from bovine skimmed milk that was coagulated using rennet and acid lactic. The LPO was obtained from whey using SPFF. To analyze the resistence of enzyme activity, the immobilized LPO was stored in pure water, phosphate buffer, milk and whey at $10^{\circ} \mathrm{C}$. The activity of LPO was monitored for 10 days. The result indicates that the LPO could be purified from whey and single band has been detected using electrophoresis method. The obtained LPO (35 U $\mathrm{mL}^{-1}$ ) was attached onto SPFF and SPBB. Maximum immobilization efficiency has been achieved by $0.6 \mathrm{~g}$ SP-FF and $0.9 \mathrm{~g}$ SP-BB. LPO activity of the immobilized LPO were able to be kept until 5 days when it was stored in whey. Other storage solution remained various LPO activity during storage. This study concluded that IE of LPO attached onto sepharoses might be reached variously depended on the sepharose type and whey as LPO source might be used for maintaining LPO activity.
\end{abstract}

Key words: Lactoperoxidase, SP sepharose fast flow, SP sepharose big beads, immobilization, remaining activity

\section{INTRODUCTION}

Lactoperoxidase (LPO), together with $\mathrm{SCN}^{-}$and $\mathrm{H}_{2} \mathrm{O}_{2}$ have been understood to generates intermediate product of $\mathrm{OSCN}^{-}$as antibacterial agent that has a broad spectrum of antimicrobial effects against bacteria, fungi and viruses. This antibacterial agent could be produced if these three components exist in the medium (Seifu et al., 2005). LPOS has been widely used as a preservative in dairy products and nondairy products (Seifu et al., 2004; Touch et al., 2004; FAO/WHO, 2005; Boots and Floris, 2006; Oghaiki et al., 2007; Fweja et al., 2008; Al-Baarri et al., 2011a).

It has been understood that whey contains large number of LPO therefore purification method of LPO from whey has been well developed (Touch et al., 2004; Zhou and Lim, 2009; 


\section{J. Name}

Al-Baarri et al., 2010). SP-Sepharose has been known to provide beneficial effect for the immobilization efficiency since SP-Sepharose almost completely immobilized LPO and reusable (Al-Baarri et al., 2010). Although, LPOS was widely used in food application but it still remained the problem of its expensiveness, therefore the immobilization of LPO was needed for the reuse of LPO.

SP Sepharose has been known as immobilization agent for capturing lactoperoxidase (Fee and Chand, 2006; Hayashi et al., 2012). SP Sepharose Fast Flow (SPFF) and SP Sepharose Big Beads (SPBB) were the common resin for immobilization since the they provide simply application, long term of use and easy for reuse (Amersham-Bioscience, 2001). If compare to other immobilization agent such as chitosan, SP Sepharoses showed higher capturization of lactoperoxidase (Al-Baarri et al., 2012). In the other hand, SP Sepharose application for immobilization of LPO resulting in the much more expensive of the use of LPO, therefore the efficient use of SP Sepharose to immobilize LPO is required. Based on related literatures, there was no documentation for the efficient use of LPO immobilization using SP Sepharose, therefore this research has been done for analyzing the maximum capturization of LPO onto SP Sepharose. This information might provide the benefit for minimum use of SP Sepharose for LPO immobilization. Since the immobilized LPO allowed the reuse of enzyme, the appropriate storage solution for keeping the enzyme activity is needed. To answer this, this research has also been done for analyzing the remaining of LPO activity after storage.

\section{MATERIALS AND METHODS}

Materials: SP Sepharose Fast Flow and SP Sepharose Big Beads were purchased from Amersham Pharmacia Biotech, Sweden (Lot. No. 10029743 and 10081054, respectively). Microbial derived rennet was purchased from Singapore and ABTS or 2,20-azino-bis (3-ethylbenz-thiazoline-6sulphonic acid) was obtained from Kagawa Science (Lot No. 7ROZC-EC) Tokyo Chemical, Industry Co. Ltd. Japan. Cow's milk was obtained from Faculty of Animal and Agricultural Sciences's farm, Diponegoro University, Semarang, Indonesia. The spectrophotometer (Mini UV-1800, Schimadzu, Japan) was used for analysis enzyme activity. Unless other compounds specified, all other compounds were reagent grade.

Preparation of whey: The whey was prepared as method performed by Al-Baarri et al. (2011b) without any modification.

LPO immobilization from whey: The procedure for immobilization of LPO was conducted as the method that was performed by Al-Baarri et al. (2010) with minor modifications. SP Sepharose Fast Flow (SPFF) was used as agent for LPO immobilization from whey. Whey at the volume of $1800 \mathrm{~mL}$ was eluted through a glass column $(3 \times 40 \mathrm{~cm})$ filled with $60 \mathrm{~g}$ of SPFF. Prior to elution, $\mathrm{SPFF}$ was washed with $300 \mathrm{~mL}$ of Phosphate Buffer (PB) (pH 6.8) containing $1 \mathrm{M} \mathrm{NaCl}$ to remove unnecessary compounds. The whey was circulated through the column using feedback tubing and a peristaltic pump. The circulation was done at the flow rate of $1.0 \mathrm{~mL} \mathrm{~min}{ }^{-1}$. After draining the whey away, the resin was washed with $300 \mathrm{~mL}$ of $0.4 \mathrm{mM} \mathrm{NaCl}$ in $0.1 \mathrm{mM}$ phosphate buffer ( $\mathrm{pH}$ 7.0) using fraction collector (10 $\mathrm{mL}$ per tube) to obtain the solution containing high concentration of LPO. Three groups of fractions (fraction number 1-10, 11-20, 21-30) were analyzed for protein profile using sodium dodecyl sulfate polyacrylamide gel electrophoresis 


\section{J. Name}

(SDS-PAGE) to check the purity. Finally, based on the SPS PAGE analysis, the fraction number 21-30 was selected for LPO activity analysis (LPO activity was $35 \mathrm{U} \mathrm{mL}^{-1}$ ). Thus, this fraction was used throughout experiment.

Determination of captured LPO onto SP sepharoses: SPFF and SPBB (0.1-1.0 g) were washed in $1 \mathrm{M} \mathrm{NaCl}$ in $\mathrm{PB} \mathrm{pH} 7.0$ and then were placed in the column $(1 \times 10 \mathrm{~cm})$. The immobilization process was started with the elution of $1 \mathrm{mI}$. $\mathrm{I} \mathrm{D} \cap$ through column. The flow rate was set into $1 \mathrm{~mL} \mathrm{~min}^{-1}$ using peristaltic pu It should be: for measurement of

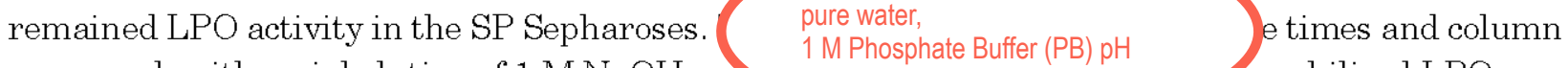
were wash with serial elution of $1 \mathrm{M} \mathrm{NaOH}$ and 7.0, milk, and whey

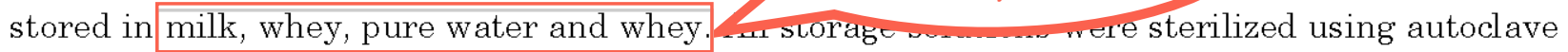
at $110^{\circ} \mathrm{C}$ for $10 \mathrm{~min}$. Immobilized LPO was stored at $4^{\circ} \mathrm{C}$ for 10 days. The remaining of LPO activity immobilized onto SP-Sepharose was calculated by eluting immobilized LPO using $1 \mathrm{M} \mathrm{NaCl}$ in PB $\mathrm{pH}$ 7.0. The LPO activity in the elution was analyzed spectrometrically.

LPO activity determination: $\mathrm{LPO}$ activity was performed as the following method: $450 \mu \mathrm{L}$ of $1.0 \mathrm{mM}$ ABTS in $10 \mathrm{mM}$ acetate buffer $(\mathrm{pH} 4.4)$ and $450 \mu \mathrm{L}$ of $0.55 \mathrm{mM} \mathrm{H}_{2} \mathrm{O}_{2}$ in pure water were gently poured into the cuvette. The enzyme $(50 \mu \mathrm{L})$ was subsequently added to cuvette. The increase of absorbance at $412 \mathrm{~nm}$ measured for $20 \mathrm{sec}$. One unit of LPO enzymatic activity was expressed as the amount of enzyme needed to oxidize $1 \mu \mathrm{mol}$ ABTS $\min ^{-1}$. The molar extinction coefficient of ABTS at $412 \mathrm{~nm}$ was $32.400 \mathrm{M}^{-1} \mathrm{~cm}^{-1}$ (Touch et al., 2004).

Immobilization efficiency: The immobilization efficiency (IE) was calculated as follows:

$$
\operatorname{IE}(\%)=\frac{E_{1}}{E_{0}} \times 100
$$

where, $\mathrm{E}_{0}$ is the LPO activity added to the SP Sepharoses $\left(\mathrm{U} \mathrm{mL}^{-1}\right)$ and $\mathrm{E}_{1}$ is the LPO activity embedded in the SP Sepharose ( $\mathrm{U} \mathrm{mL}^{-1}$ ) (Al-Baarri et al., 2010).

\section{RESULTS AND DISCUSSION}

Purification LPO: Whey has a lot of enzymes and it is available in low cost because whey is by product of dairy manufacture so it is the challenge to use whey as enzyme sources including LPO. The LPO activity and band(s) of the solution obtained from the elution of $1 \mathrm{M} \mathrm{NaCl}$ in $\mathrm{PB} \mathrm{pH} 7.0$ through SPFF containing LPO were checked using spectrophotometer and SDS PAGE, respectively. As mention in methods, SPFF containing LPO was generated from whey that was eluted through SPFF column. The result of LPO activity was $27.7 \pm 2.9,39.5 \pm 4.5$ and $35.2 \pm 3.4 \mathrm{U} \mathrm{mL}^{-1}$ for fraction number 1-10, 11-20, 21-30, respectively (data not presented). The highest of LPO activity was group of fraction number 11-20, however since the band of this group showed two bands indicating two protein was detected, for whole of experiment, group of fraction number 21-30 was used. This group showed single band indicating only LPO that was captured by SPFF.

In this research SPFF was used to obtain LPO since this ion exchange resin has diameter 45-165 $\mu \mathrm{m}$ resulting in the wider of surface area than SPBB (Amersham-Bioscience, 2001). In line with this result, Touch et al. (2004) used SPFF for purifying LPO from whey resulting in the good 


\section{J. Name}

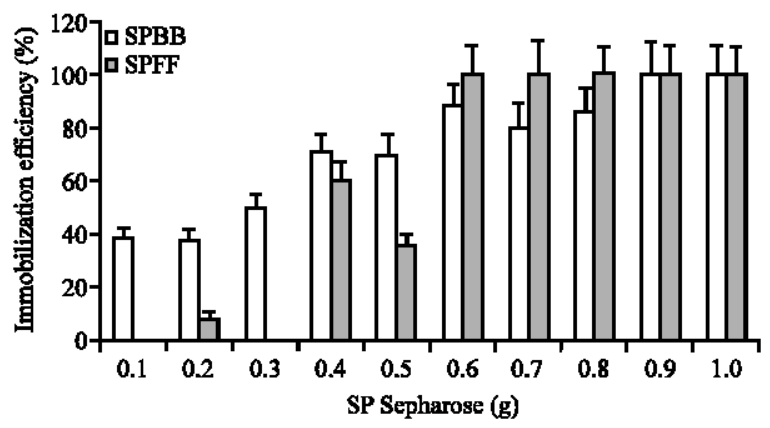

Fig. 1: Immobilization efficiency (IE) of LPO on two types of resin, i.e., SP Sepharose Big Beads (SPBB) and SP Sepharose Fast Flow (SPFF). Two types of resin (0.1-1.0 g) was used to immobilized $1 \mathrm{~mL}$ of LPO (35 $\left.\mathrm{U} \mathrm{mL}{ }^{-1}\right)$. Flow rate has been set to $1 \mathrm{~mL} \mathrm{~min}^{-1}$ using peristaltic pump. Values are means of three sets of experiments, Error bars represent standard errors of the mean

ability to catch LPO (108 $\left.\mathrm{U} \mathrm{mL}^{-1}\right)$. The activity of LPO in this research was less than that of other researcher since the absence of microfiltration step in this research. It has been known that the microfiltration might concentrate the enzyme resulting in the high activity of LPO.

Immobilization efficiency: Immobilization efficiency plays an important role for determination of immobilization agent. This research determined Immobilization Efficiency (IE) of LPO using SPFF dan SPBB (Fig. 1). The volume of SP Sepharoses used in this experiment had a range from 0.1 to $1.0 \mathrm{~g}$ to catch the $\mathrm{LPO}$ at initial activity of $35.2 \pm 3.4 \mathrm{U} \mathrm{mL}^{-1}$. The increase of IE was found as an increase of SP Sepharoses's weight. As describe in Fig. 1, when the $0.6 \mathrm{~g}$ of SPFF was employed, the IE achieved 100\% indicating all of LPO employed was able to be captured by SPFF. When the weight of SPFF was increased, the IE was in steady state maximumly. An increase SPBB from 0.1 to $1.0 \mathrm{~g}$ elevated the IE from 38.6 to $100 \%$. However, $0.9 \mathrm{~g}$ of SPBB completely captured $\mathrm{LPO}$ resulting the $\mathrm{IE}$ of $100 \%$. One gram of SPFF was reported to have a maximum capture of LPO in $300 \mathrm{~mL}$ whey (equal to $750 \mathrm{U} \mathrm{mL}^{-1} \mathrm{LPO}$ activity) (Al-Baarri et al., 2010). This can be explained that the capture depended on the quantity of enzymes per mililiter. This n It should be: of LPO resulting in the loss of LPO activity.

Since the SPFF and SPBB provided the maximum IE at 0.6 and amounts of SP Sepharoses has been used in the rest of experiment $>7.0$, milk, and whey $\mathrm{SPFF}$ and SPBB was stored in the various storage solutions: Pure water, PB, milk and whey for 10 days at $10^{\circ} \mathrm{C}$.

Remaining LPO activity during storage: The percentage of remaining immobilized LPO activity stored at $10^{\circ} \mathrm{C}$ for 10 days in various storage solutions is shown in Fig. 2a and b. LPO activity of immobilized LPO was measured after purging the LPO attached onto SP Sepharose with $1 \mathrm{M} \mathrm{NaCl}$ in $\mathrm{PB} \mathrm{pH} \mathrm{7.0.} \mathrm{The} \mathrm{percentage} \mathrm{of} \mathrm{remaining} \mathrm{LPO} \mathrm{activity} \mathrm{was} \mathrm{determined} \mathrm{by} \mathrm{comparing}$ the LPO activity after storage to the initial immobilized LPO at first day of storage.

The percentage of LPO activity attached onto SPBB and SPFF is shown on Fig. 2a and b, respectively. Based on Fig. 2a, whey was able to maintain 100\% enzyme activity of LPO attached onto SPBB within 4 days. The extention of storage time resulted in the remarkable 


\section{J. Name}
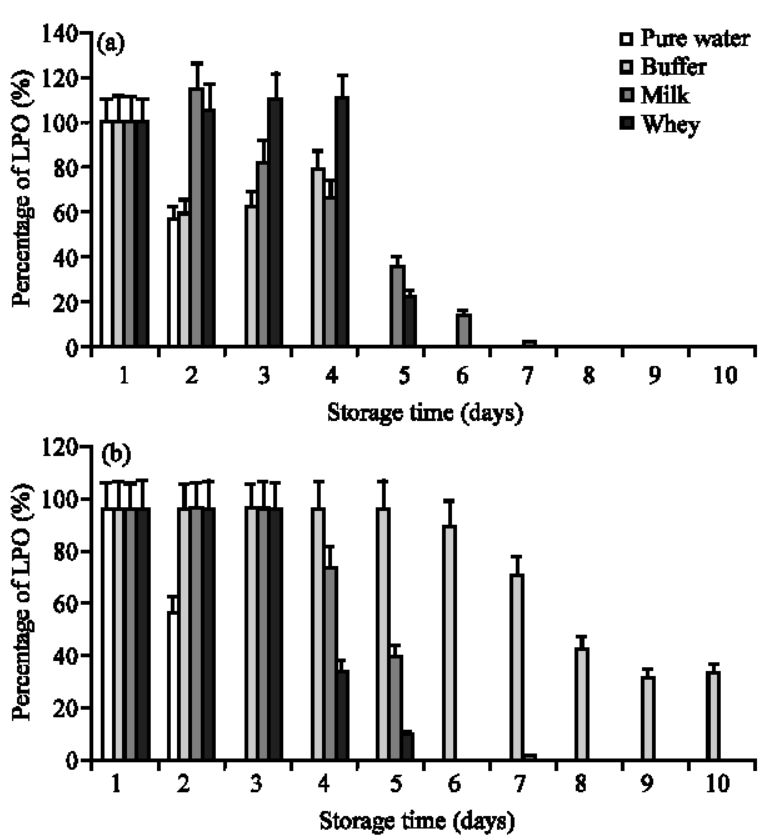

Fig. 2(a-b): (a) Percentage of remaining LPO activity attached onto SP Sepharose Big Beads (SPBB) during 10 days of storage at $10^{\circ} \mathrm{C}$ in various storage solutions. This experiment used $1 \mathrm{~g}$ of SPBB for immobilizing $1 \mathrm{~mL}$ of LPO $\left(35 \mathrm{U} \mathrm{mL}^{-1}\right)$. Immediately after immobilization, SPBB then was stored in sterilized pure water, phosphate buffer, milk and whey for 10 days at $10^{\circ} \mathrm{C}$. Values are mean of three sets of experiments. Error bars represent standard errors of the mean and (b) Percentage of remaining LPO activity attached onto SP Sepharose Fast Flow (SPFF) during 10 days of storage at $10^{\circ} \mathrm{C}$ in various storage solution. This experiment used $1 \mathrm{~g}$ of SPFF for immobilizing $1 \mathrm{~mL}$ of LPO (35 $\left.\mathrm{U} \mathrm{mL}^{-1}\right)$. After immobilization, SPFF was stored in sterilized pure water, phosphate buffer, milk and whey. Values are mean of three sets of experiments. Error bars represent standard errors of the mean

reduction of remaining LPO activity. Milk was able to maintain the LPO activity at seven days of storage even though the remaining of LPO activity at that time was very negligible in amount $(2.3 \%)$.

As previously mentioned, whey was able to completely keep LPO activity within 4 days of storage. This can be explained that whey components support the activity of LPO. It has been studied that LPO activity might be inhibited by casein (Singh et al., 2009) while the casein has been removed from whey.

The remaining of LPO activity attached onto SPFF during 10 days of storage at $10^{\circ} \mathrm{C}$ is shown on Fig. 2b. PB was able to maintain $100 \%$ of LPO activity within 5 days of storage. The milk and whey were able to keep 100\% of LPO activity within 3 days of storage. The elevation of storage time until 5 days in whey could keep enzyme activity although the remaining enzyme activity was small amount $(10.08 \%)$. Based on the availability, also since LPO was simply derived from whey, the storage of immobilized LPO in whey should keep its activity up to 5 days of storage. Therefore it is suggested that immobilized LPO should be stored in whey. 


\section{J. Name}

\section{CONCLUSION}

The results can be concluded that LPO could be purified from whey using fraction number 21-30. One mililiter of LPO (35 $\mathrm{U} \mathrm{mL}^{-1}$ ) could be completely immobilized onto $0.6 \mathrm{~g} \mathrm{SPFF}$ or $0.9 \mathrm{~g}$ SPBB (immobilization efficiency was $100 \%$ ). Among various storage solution, whey was able to keep $100 \%$ of LPO activity up to 5 days of storage.

\section{ACKNOWLEDGMENTS}

This study was supported by funds from the Ministry of Research and Technology of Republic of Indonesia for the project "Insentif Riset SINAS" with Grant Project No. RT-2013-2163.

\section{REFERENCES}

Al-Baarri, A.N., M. Ogawa and S. Hayakawa, 2010. Scale-up studies on immobilization of lactoperoxidase using milk whey for producing antimicrobial agent. J. Indonesian Trop. Anim. Agric., 35: 185-191.

Al-Baarri, A.N., M. Hayashi, M. Ogawa and S. Hayakawa, 2011a. Effects of mono-and disaccharides on the antimicrobial activity of bovine lactoperoxidase system. J. Food Prot., 74: 134-139.

Al-Baarri, A.N., M. Ogawa and S. Hayakawa, 2011b. Application of lactoperoxidase system using bovine whey and the effect of storage condition on lactoperoxidase activity. Int. J. Dairy Sci., 6: $72-78$.

Al-Baarri, A.N., M. Ogawa, T. Visalsok and S. Hayakawa, 2012. Lactoperoxidase immobilized onto various beads for producing natural preservatives solution. J. Applied Food Technol., 1: 4-6.

Amersham-Bioscience, 2001. Use of sodium hydroxide for cleaning and sanitizing chromatography media and systems. Application Note 18-1124-57 AD, Process Chromatography, Amersham Bioscience, USA. http://risk.management6.com/Use-of-sodium-hydroxide-for-cleaning-andsanitizing-chromatography-download-w15138.pdf.

Boots, J.W. and R. Floris, 2006. Lactoperoxidase: From catalytic mechanism to practical applications. Int. Dairy J., 16: 1272-1276.

FAO/WHO, 2005. Benefits and potential risks of the lactoperoxidase system of raw milk preservation. Report of an FAO/WHO Technical Meeting, November 28-December 2, 2005, FAO Headquarters, Rome, Italy, pp: 1-73.

Fee, C.J. and A. Chand, 2006. Capture of lactoferrin and lactoperoxidase from raw whole milk by cation exchange chromatography. Separation Purification Technol., 48: 143-149.

Fweja, L.W.T., M.J. Lewis and A.S. Grandison, 2008. Challenge testing the lactoperoxidase system against a range of bacteria using different activation agents. J. Dairy Sci., 91: $2566-2574$.

Hayashi, M., S. Naknukool, S. Hayakawa, M. Ogawa and A.B.A. Ni'matulah, 2012. Enhancement of antimicrobial activity of a lactoperoxidase system by carrot extract and $\alpha$-carotene. Food Chem., 130: 541-546.

Oghaiki, N.A., F. Fonteh, P. Kamga, S. Mendi and H. Imele, 2007. Activation of the lsctoperoxidise system as a method of preserving raw milk in areas without cooling facilities. Afr. J. Food Agric. Nutr. Dev., 7: 1-14.

Seifu, E., E.M. Buys and E.F. Donkin, 2004. Quality aspects of Gouda cheese made from goat milk preserved by the lactoperoxidase system. Int. Dairy J., 14: 581-589. 


\section{J. Name}

Seifu, E., E.M. Buys and E.F. Donkin, 2005. Significance of the lactoperoxidase system in the dairy industry and its potential applications: A review. Trends Food Sci. Technol., 16: 137-154.

Singh, A.K., N. Singh, S. Sharma, K. Shin and M. Takase et al., 2009. Inhibition of lactoperoxidase by its own catalytic product: Crystal structure of the hypothiocyanate-inhibited bovine lactoperoxidase at 2.3-A resolution. Biophys. J., 96: 646-654.

Touch, V., S. Hayakawa, S. Yamada and S. Kaneko, 2004. Effects of a lactoperoxidase-thiocyanatehydrogen peroxide system on Salmonella enteritidis in animal or vegetable foods. Int. J. Food Microbiol., 93: 175-183.

Zhou, Y. and L.T. Lim, 2009. Activation of lactoperoxidase system in milk by glucose oxidase immobilized in electrospun polylactide microfibers. J. Food Sci., 74: C170-C176. 
Dear The Editor of

International Journal of Dairy Science

Thank you for your kind to process our article to publish at your journal. We received the final proof of our article entitled: "Resistence of Immobilized Lactoperoxidase Activity from Bovine Whey Against Storage Solutions" (article number 57374) for second time.

In this time, we could not see our revision (the article seems similar to previous article). Through this letter, we hope the correction for our final proof's article are able to be received.

Here we listed the correction for final proof.

\begin{tabular}{|l|l|l|}
\hline Position & It was written & It should be written \\
\hline $\begin{array}{l}\text { Page 1 on the } \\
\begin{array}{l}\text { Aorresponding } \\
\text { Author }\end{array}\end{array}$ & $\begin{array}{l}\text { Dwi Novrina Nawangsari, } \\
\text { Department of Animal Product } \\
\text { Technology, Faculty of Animal } \\
\text { and Agricultural Sciences, } \\
\text { Diponegoro University, } \\
\text { Semarang, Indonesia }\end{array}$ & $\begin{array}{l}\text { Ahmad Ni'matullah Al-Baarri, } \\
\text { Department of Food } \\
\text { Technology, Faculty of } \\
\text { Animal and Agricultural } \\
\text { Sciences, } \\
\text { Diponegoro University, } \\
\text { Semarang, Indonesia } \\
\text { (albari@undip.ac.id) }\end{array}$ \\
\hline $\begin{array}{l}\text { Page } 3 \text { on the } \\
\text { sub title: } \\
\begin{array}{l}\text { Determination } \\
\text { of Captured } \\
\text { LPO ... }\end{array}\end{array}$ & $\begin{array}{l}\text { The immobilized LPO was } \\
\text { stored in milk, whey, pure } \\
\text { water and whey }\end{array}$ & $\begin{array}{l}\text { The immobilized LPO was } \\
\text { stored in pure water, PB, } \\
\text { milk, and whey }\end{array}$ \\
\hline
\end{tabular}

Again, thank you very much for your attention and we hope this correction are able to be implemented in our article.

Sincerely,

Ahmad Ni'matullah Al-Baarri

Author 


\section{SCIENCE ALERT}

www.scialert.com

P.O.Box 126208 Deira Dubai, UAE.

Jan 23, 2014

Mr. Ahmad N AL-Baarri,

Diponegoro University

Subject: Acceptance Letter for Article No. 57374-IJDS-AJ

It's a great pleasure for us to inform you that below mentioned manuscript has been accepted for publication in International Journal of Dairy Science as Research Article on the recommendation of the reviewers.

Title: RESISTANCE OF IMMOBILIZED LACTOPEROXIDASE ACTIVITY FROM BOVINE WHEY AGAINST STORAGE SOLUTIONS

Author's Name: Dwi Novrina Nawangsari, Ahmad Nimatullah Al-Baarri and Sri Mulyani

Receiving Date: August 02, 2013

Revised on: October 26, 2013

Accepted on: October 31, 2013

Published on: January 20, 2014

Regards

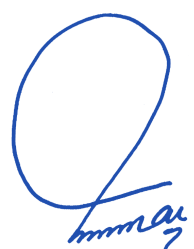

M. Imran Pasha

Publication Manager 


\section{RESISTANCE OF IMMOBILIZED}

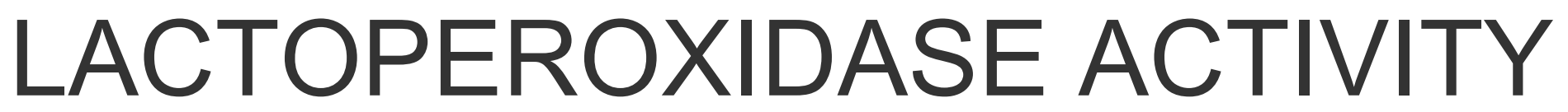

FROM BOVINE WHEY

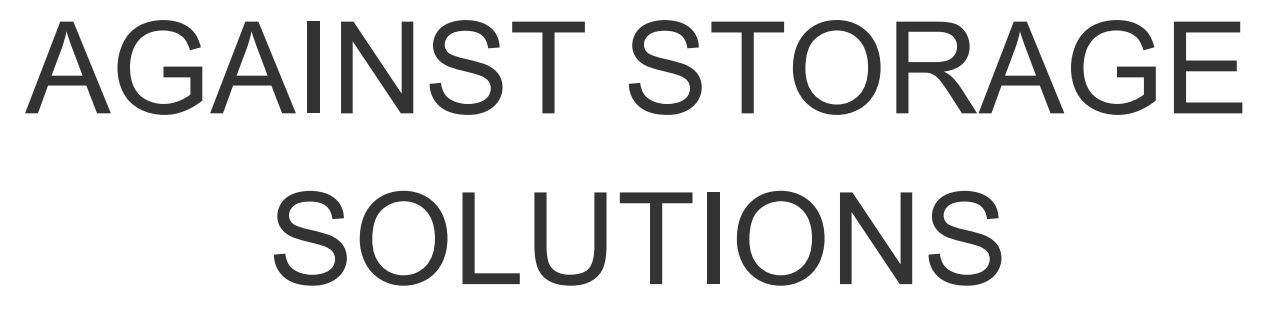

by Dwi Novrina Nawangsari

Submission date: 04-Sep-2019 02:55AM (UTC+0700)

Submission ID: 1166759461

File name: 57374-IJDS-AJ-evaluated-Hypered_RAW_MANUSCRIPT.doc (331.5K)

Word count: 2915

Character count: 15230 
We have received the response from reviewer 1 and reviewer 2 to ouf article, however we found the question from reviewer 2 only:

Al Barri,2011 missed, Also the result of LPO activity why not presented in a table Also The captions of the figures must be written at the tep of the figures and

must be clear and explain the figures: Our respenses:

Al Baarri, 2011 has beenchanged to Al Baarfi, 20110. We are serfy, it should be added with "2" after "2011"

ЏPOactivity did not appear in a table since we would like to show the differences between treatments (sterage). We believe that the deseription through percentage in a figure is much easier to be understood

The caption has been moved inte the top of figure and the explanation of figure has been eempleted.

Sincerely.

Ahmad Ni'matullah Al Baarfi
$4 \quad$ Formatted: Left, Indent: Left: $0.39 "$, Right: 0.76

Formatted: Font: Not Bold

Formatted: Left

Formatted: Left, Numbered + Level: $1+$ Numbering Style: $1,2,3, \ldots+$ Start at: $1+$ Alignment: Left + Aligned at: 0.25 + Indent at: $0.5^{\prime \prime}$

\section{Formatted: Left}

Formatted: Font: Not Bold 


\section{RESISTANCE OF IMMOBILIZED LACTOPEROXIDASE ACTIVITY FROM BOVINE WHEY AGAINST STORAGE SOLUTIONS}

Dwi Novrina Nawangsari ${ }^{1}$, Ahmad Ni_matullah Al-Baarri ${ }^{2+1}{ }_{2}$ and-Sri Mulyani ${ }^{22}$, Anang Mohamad Legowo ${ }^{2)}$, V. Privo Bintoro ${ }^{2)}$

1)Department of Animal Product Technology; Faculty of Animal and Agricultural Sciences; Diponegoro University, Semarang, Indonesia

2)Department of Food Technology, Faculty of Animal and Agricultural Sciences; Diponegoro University, Semarang, Indonesia

\section{ABSTRACT}

Lactoperoxidase (LPO) could be simply obtained from whey through immobilization using a cation exchange resin of SP Sepharose. LPO received high attention since the antimicrobial properties of LPO system (LPOS) that are consisted of $\mathrm{LPO}, \mathrm{SCN}^{-}$, and $\mathrm{H}_{2} \mathrm{O}_{2}$ was able to generate $\mathrm{OSCN}^{-}$for strong antimicrobial agents. This study was done to analyze the immobilization efficiency of LPO onto two types of sepharose: SP-Sepharose Fast Flow (SPFF) and SP-Sepharose Big Beads (SPBB). The remaining of LPO's activity (\%) against storage solution was also observed. The whey was obtained from bovine skimmed milk that was coagulated using rennet and acid lactic. The LPO was obtained from whey using SPFF. To analyze the remaining-resistence of immebilized LPO-enzyme activity, the immobilized LPO was stored in pure water, phosphate buffer, milk, and whey at $10^{\circ} \mathrm{C}$. The activity of LPO was monitored for 10 days. The result indicates that the LPO could be purified from whey and single band has been detected using electrophoresis method. The obtained LPO (35 $\mathrm{U} / \mathrm{ml}$ ) was attached onto SPFF and SPBB. Maximum immobilization efficiency has been achieved It was entuded that by $0.6 \mathrm{~g}$ SP-FF and $0.9 \mathrm{~g}$ SP-BB were able to ahieved $100^{\circ}$ 。 ef immebilization fieiency (IE). LPO activity of the immobilized LPO ente Sephareses-were able to be kept until 5 days when it was stored in whey. Other storage solution remained various LPO activity during storage. This research concluded that IE of LPO attached onto sepharoses might be reached variously depended on the sepharose type and whey as LPO source might be used for maintaining LPO activity

Key words: Lactoperoxidase, SP Sepharose Fast Flow, SP Sepharose Big Beads, immobilization, remaining activity.
Commented [ANA1]: Please allow us to add the co-authors
since this author has a big contribution to our experiments and since this author has a big contribution to our experiments and
article writing. The contribution of authors have been mentioned in cover letter.

Commented [02]: The cover letter for this manuscript is not provided by the author. Download sample cover letter from the link and submit duly filled Cover Letter with all your new submissions http://scialert.net/coverletter.doc

Commented [ANA3]: Cover letter has been made and author has sent this cover letter along with this article.

Commented [04]: End the paragraph of abstract section with a clear cut conclusion of study, but length of abstract section should not exceed from more than 250 words.

Commented [ANA5]: Cover letter has been added and sent via email

Commented [06]: Check the spelling of yellow highlighted words. 


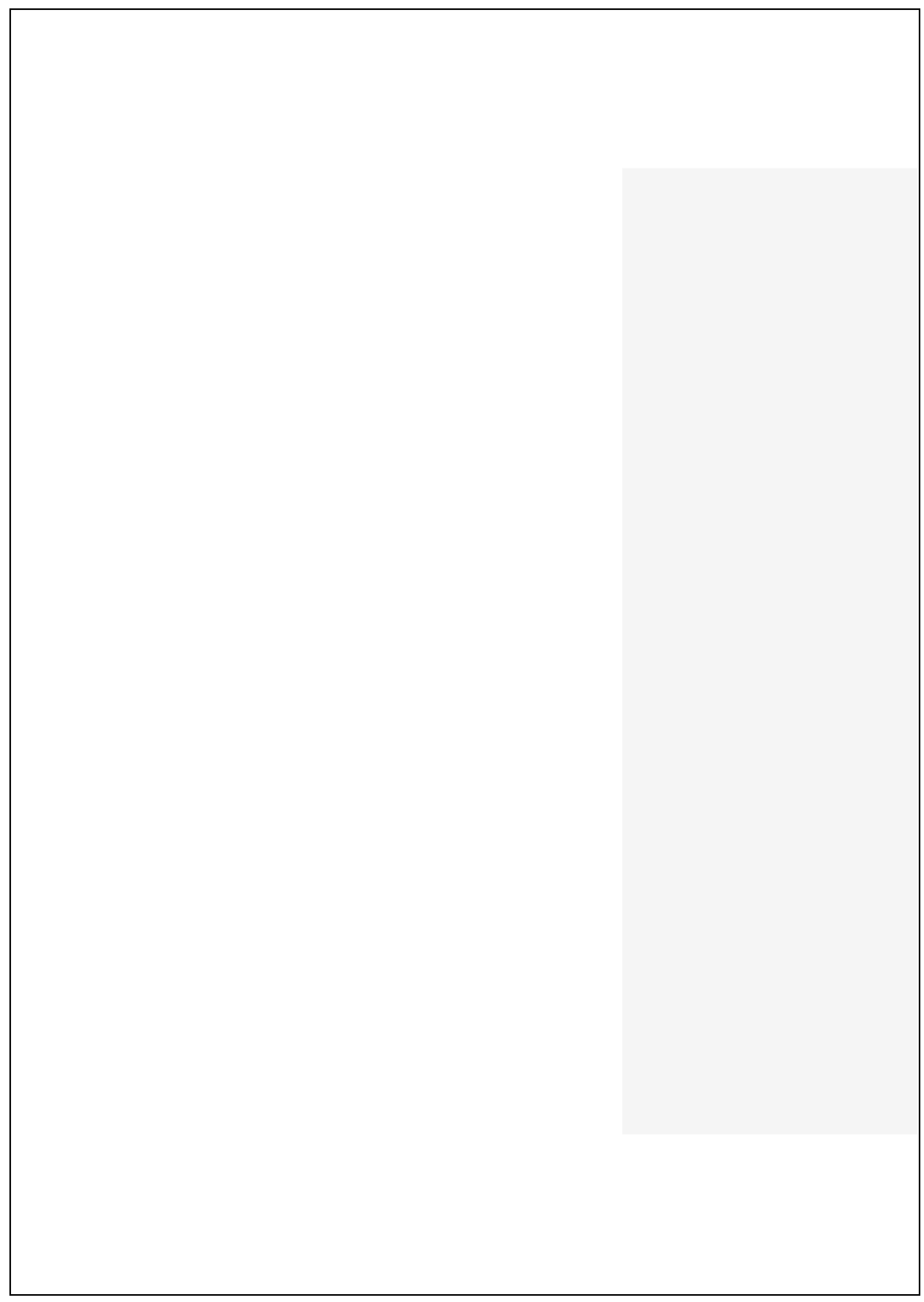




\section{INTRODUCTION}

Lactoperoxidase (LPO), together with $\mathrm{SCN}^{-}$and $\mathrm{H}_{2} \mathrm{O}_{2}$ have been understood to generates intermediate product of $\mathrm{OSCN}^{-}$as antibacterial agent that has a broad spectrum of antimicrobial effects against bacteria, fungi and viruses. This antibacterial agent could be produced if these three components exists in the medium (Seifu et al., 2005, Al-Baarri. 2011a). LPOS has been widely used as a preservative in dairy products and nondairy products (Seifu et al., 2004, Touch et al., 2004, FAO/WHO, 2005, Boots and Floris, 2006, Oghaiki et al, 2007, Fweja et al., 2008, Al-Baarri et al., 2011a).

It has been understood that whey contains large number of LPO therefore purification method of LPO from whey has been well developed (Touch et al., 2004, Zhou and Lim. $\underline{2009}$, Al-Baarri et al.. 2010). SP-Sepharose has been known to provide beneficial effect for the immobilization efficiency since SP-Sepharose almost completely immobilized LPO and reusable (Al-Baarri et al., 2010). Although LPOS was widely used in food application but it still remained the problem of its expensiveness, therefore the immobilization of LPO was needed for the reuse of LPO.

SP Sepharose has been known as appropriate-immobilization agent for capturing lactoperoxidase (Fee and Chand. 2006; Hayashi et al.. 2012). SP Sepharose Fast Flow (SPFF) and SP Sepharose Big Beads (SPBB) were the common resin for immobilization since the they provide simply application, long term of use, and easy for reuse (Amersham-Bioscience. 2001). If compare to other immobilization agent such as chitosan, SP Sepharoses showed higher capturization of lactoperoxidase (Al-Baarri et al., 2012). In the other hand, SP Sepharose application for immobilization of LPO resulting in the much more expensive of the use of LPO, therefore the efficient use of SP Sepharose to immobilize LPO is required. Based on related literatures-, there was no documentation for the efficient use of LPO immobilization using SP Sepharose, therefore this research has been done for analyzing the Com
text. maximum capturization of LPO onto SP Sepharose. This information might provide the benefit for minimum use of SP Sepharose for LPO immobilization. Since the immobilized LPO allowed the reuse of enzyme, the appropriate storage solution for keeping the enzyme activity is needed. To answer this, this research has also been done for analyzing the remaining of LPO activity after storage so, I did not change this word.

\section{MATERIALS AND METHODS}

deseriptive analysis was used for deseribing aetivity of $L P O$ in all treatment

Commented [010]: Provide some detail of sued statistical 

Amersham Pharmacia Biotech, Sweden (Lot. No. 10029743 and No. 10081054 , respectively). Microbial derived rennet was purchased from Singapore and ABTS or 2,20-azino-bis (3ethylbenz-thiazoline-6-sulphonic acid) erABTS was obtained from Kagawa Science (Lot No. 7ROZCEC) Tokyo Chemical, Industry Co. Ltd. Japan. Cow's milk was obtained from Faculty of Animal and Agricultural Sciences's farm, Diponegoro University, Semarang, Indonesia. The spectrophotometer (Mini UV-1800, Schimadzu, Japan) was used for analysis enzyme activity. Unless other compounds specified, all other compounds were reagent grade.

\section{Preparation of whey}

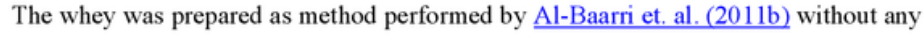
modification.

\section{LPO Immobilization from Whey}

The procedure for immobilization of LPO immobilization-was conducted as the method that was performed by Al-Baarri et al., 2010 with minor modifications. SP Sepharose Fast Flow (SPFF) was used as-a agent for LPO immobilization from whey. Whey at the volume of $1800 \mathrm{ml}$ was eluted through a glass column $(3 \times 40 \mathrm{~cm})$ filled with $60 \mathrm{~g}$ of SP-FF. Prior to elution, SPFF was washed with $300 \mathrm{ml}$ of phosphate buffer $(\mathrm{PB})(\mathrm{pH} 6,8)$ containing $1 \mathrm{M} \mathrm{NaCl}$ to remove unnecessary compounds. The whey was circulated through the column using feedback tubing and a peristaltic pump. The circulation was done at the flow rate of 1.0 $\mathrm{ml} / \mathrm{min}$. After draining the whey away, the resin was washed with $300 \mathrm{ml}$ of $0.4 \mathrm{mM} \mathrm{NaCl}$ in $0.1 \mathrm{mM}$ phosphate buffer $(\mathrm{pH} 7.0)$ using fraction collector $(10 \mathrm{ml}$ per tube) to obtain the solution containing high concentration of LPO. Three grempgroups of fractions (fraction number 1-10, 11-20, 21-30) were analyzed for protein profile using sodium dodecyl sulfate polyacrylamide gel electrophoresis (SDS PAGE) SDS PAGE-to check the purity. Finally, based on the SPS PAGE analysis, the fraction number 21-30 was analyzed-selected for LPO activity analysis ( $(\mathrm{LPO}$ activity was $35 \mathrm{U} / \mathrm{ml})$. Thus, this fraction-and was used throughout experiment.

\section{Determination of Captured LPO onto SP Sepharoses}

SP-FF and SP-BB $(0.1-1.0 \mathrm{~g})$ were washed in $1 \mathrm{M} \mathrm{NaCl}$ in $\mathrm{PB} \mathrm{pH} 7.0$ and then were placed in the column $(1 \times 10 \mathrm{~cm})$. The immobilization process was started with the elution of 1 $\mathrm{ml}$ of LPO through column. The flow rate was set into $1 \mathrm{ml} / \mathrm{min}_{-}$tte using peristaltic pump. 
The output was collected for measurement of remained LPO activity in the SP Sepharoses. This experiment was repeated three times and column were wash with serial elution of $1 \mathrm{M}$ $\mathrm{NaOH}$ and pure water, respectively. The immobilized LPO was stored in milk, whey, pure water and whey. All storage solutions were sterilized using autoclave at $110^{\circ} \mathrm{C}$ for 10 minutes. Immobilized LPO was stored at $4^{\circ} \mathrm{C}$ for 10 days. The remaining of LPO activity immobilized onto SP-Sepharose was calculated by eluting immobilized LPO using $1 \mathrm{M} \mathrm{NaCl}$ in $\mathrm{PB} \mathrm{pH}$ 7.0. The LPO activity in the elution was analyzed spectrometrically.

\section{LPO Activity Determination}

LPO activity was performed as the following method: $450 \mu \mathrm{l}$ of $1.0 \mathrm{mM} \mathrm{ABTS}$ in 10 $\mathrm{mM}$ acetate buffer ( $\mathrm{pH} \mathrm{4.4)}$ and $450 \mu \mathrm{l}$ of $0.55 \mathrm{mM} \mathrm{H}_{2} \mathrm{O}_{2}$ in pure water were gently poured into the cuvette. The enzyme $(50 \mu \mathrm{l})$ was subsequently added to cuvette. The increase of absorbance at $412 \mathrm{~nm}$ measured for 20 second. One unit of LPO enzymatic activity was expressed as the amount of enzyme needed to oxidize $1 \mu \mathrm{mol}$ ABTS $/ \mathrm{min}$. The molar extinction coefficient of ABTS at $412 \mathrm{~nm}$ was $32.400 \mathrm{M}^{-1} \mathrm{~cm}^{-1}$ (Touch et al., 2004).

\section{Immobilization Efficiency}

The immobilization efficiency (IE) was calculated as follows: $\operatorname{IE}(\%)=\mathrm{E} 1 / \mathrm{E} 0 \times 100$, where E0 is the LPO activity added to the SP Sepharoses $(\mathrm{U} / \mathrm{ml})$ and E1 is the LPO activity embedded in the SP Sepharose (U/ml) (Al-Baarri et al., 2010).

\section{RESULTS AND DISSCUSSION}

\section{Purification LPO}

Whey has a lot of enzymes and it is available in low cost because whey is by product of dairy manufacture so it is the challenge to use whey as enzyme sources including LPO. Table 1-shews - The LPO activity $\%$ and band (s) of the solution obtained from the elution of 1 $\mathrm{M} \mathrm{NaCl}$ in $\mathrm{PB} \mathrm{pH} 7.0$ through SPFF containing $\mathrm{LPO}_{\text {were checked using spectrophotometer }}$ and SDS PAGE, respectively. As mention in methods, SPFF containing LPO was generated from whey that was eluted through SPFF column. The result of LPO activity was $27.7 \pm 2.9$, $39.5 \pm 4.5$, and $35.2 \pm 3.4 \mathrm{U} / \mathrm{ml}$ for fraction number $1-10,11-20,21-30$, respectively (data not presented). As-shewn in Table 1, the highest of LPO activity was group of fraction number 11-20, however since the band of this group showed two bands indicating two protein was Commented [013]: Some numeric values mentioned in text are not in accordance with their respective tabular data. For your
convenience some of those values have been yellow highlighted. correct all data irregularities by comparing numeric values given in text with their respective tabular data. 
In this research SPFF was used to obtain LPO since this ion exchange resin has diameter $45-165 \mu \mathrm{m}$ resulting in the wider of surface area than SPBB (AmershamBioscience, 2001). In line with this result, Touch et al., 2004 used SPFF for purifying LPO from whey resulting in the good ability to catch LPO $\left(108_{-} \mathrm{U} / \mathrm{ml}\right)$. The activity of LPO in this research was less than that of other researcher since the absence of microfiltration step in this research. It has been known that the microfiltration might concentrate the enzyme resulting in the high activity of LPO.

\section{Immobilization Efficiency}

Immobilization efficiency plays an important role for determination of immobilization agent. This research determined immobilization efficiency (IE) of LPO using SPFF dan SPBB (Figure 1). The volume of SP Sepharoses used in this experiment had a range from 0.1 to $1.0 \mathrm{~g}$ to catch the LPO at initial activity of $35.2 \pm 3.4 \mathrm{U} / \mathrm{ml}$. The increase of IE was found as an increase of SP Sepharoses's weight. As describe in Figure 1, Figure 1-shews when the $0.6 \mathrm{~g}$ of SPFF was employed, the IE achieved $100 \%$ indicating all of LPO employed was able to be captured by SPFF. When the weight of SPFF was increased, the IE was in steady state maximumly. An increase SPBB from 0.1 to $1.0 \mathrm{~g}$ elevated the IE from 38.6 to $100 \%$. However, $0.9 \mathrm{~g}$ of SPBB completely captured LPO resulting the IE of $100 \%$. One gram of SPFF was reported to have a maximum capture of LPO in $300 \mathrm{ml}$ whey (equal to $750 \mathrm{U} / \mathrm{ml}$ LPO activity) (Al-Baarri et al., 2010). This can be explained that the capture might be depended on the quantity of enzymes per mililiter. This research used high activity of LPO resulting in the loss of LPO activity.

Since the SPFF and SPBB provided the maximum IE at 0.6 and $0.9 \mathrm{~g}$, respectively, thus these-ameuntthese amounts of SP Spepharoses has been used in the rest of experiment. The LPO immobilized on to SPFF and SPBB was stored in the various storage solutions: pure water, $\mathrm{PB}$, milk, and whey for 10 days in $10^{\circ} \mathrm{C}$.

\section{Remaining LPO Activity During Storage}

The percentage of remaining immobilized LPO activity stored at $10^{\circ} \mathrm{C}$ for 10 days in various storage solutions is shown in Figure $2 \underline{2 a}$ and $2 \mathrm{~b}$. LPO activity of immobilized LPO was measured after purging the LPO attached onto SP Sepharose with $1 \mathrm{M} \mathrm{NaCl}$ in $\mathrm{PB}$ pH 7.0. The percentage of remaining LPO activity was determined by comparing the LPO activity after storage to the initial immobilized LPO at first day of storage. 
The percentage of LPO activity attached onto SPBB and SPFF is shown on Figure 2a and Figure $2 \mathrm{~b}$, respectively. Based on Figure $2 \mathrm{a}$, whey was able to maintain $100 \% \mathrm{LP}$ enzyme activity of LPO attached onto SPBB within 4 days. The extention of storage time resulted in the remarkable reduction of remaining LPO activity. Milk was able to maintain the LPO activity at seven days of storage even though the remaining of LPO activity at that time was very negligible in amount $(2.3 \%)$.

As previously mentioned, whey was able to completely keep LPO activity within 4 days of storage. This can be explained that whey components support the activity of LPO. It has been studied that LPO activity might be inhibited by casein (Singh et al., 2009) while the casein has been removed from whey.

The remaining of LPO activity attached onto SPFF during 10 days of storage at $10^{\circ} \mathrm{C}$ is shown on Figure 2b. PB was able to maintain $100 \%$ of LPO activity within 5 days of storage. The milk and whey were able to keep $100 \%$ of LPO activity within 3 days of storage. The elevation of storage time until 5 days in whey could keep enzyme activity although the remaining enzyme activity was small amount (10.08\%). Based on the availability, also -since LPO was simply derived from whey, the storage of immobilized LPO in whey should keep its activity up to 5 days of storage. Therefore it is suggested that immobilized LPO should be stored in whey.

\section{CONCLUSION}

The results can be concluded that LPO could be purified from whey using fraction number 21-30. One mililiter of LPO $(35 \mathrm{U} / \mathrm{ml})$ could be completely immobilized onto $0.6 \mathrm{~g}$ SPFF or $0.9 \mathrm{~g}$ SPBB (immobilization efficiency was $100 \%$ ). Among various storage solution, whey was able to keep $100 \%$ of LPO activity up to 5 days of storage.

\section{ACKNOWLEDGMENT}

This work was supported by funds from the Ministry of Research and Technology of Republic of Indonesia for the project "Insentif Riset SINAS" with grant project number RT2013-2163.

\section{REFERENCES}

AN,2011.LactoperoxidaseActivityonBovineWheyatCriticalTemperatureStorageUnplublisheddatat disaccharides on the antimicrobial activity of bovine lactoperoxidase system. J. Food Prot., 74: 134-139.

Commented [ANA17]: I have double check for the explanation of figure and proper figure

Formatted: Indent: First line: $0^{\prime \prime}$
acknoledgment


Al-Baarri, A.N., M. Ogawa and S. Hayakawa, 2010. Scale-up studies on immobilization of lactoperoxidase using milk whey for producing antimicrobial agent. J. Indonesian Trop. Anim. Agric., 35: 185-191.

\section{$1174454 j a$}

Al-Baarri, A.N., M. Ogawa and S. Hayakawa, 2011b. Application of lactoperoxidase system using bovine whey and the effect of storage condition on lactoperoxidase activity. Int. J. Dairy Sci., 6: 72-78.

$671120 j a$

Al-Baarri, A.N., M. Ogawa, T. Visalsok and S. Hayakawa, 2012. Lactoperoxidase immobilized onto various beads for producing natural preservatives solution. J. Applied Food Technol., 1: 4-6.

$1174455 j a$

Amersham-Bioscience, 2001. Use of sodium hydroxide for cleaning and sanitizing chromatography media and systems. Application Note 18-1124-57 AD, Process Chromatography, Amersham Bioscience, USA.

\section{$62223 a n$}

Oghaiki, N.A., F. Fonteh, P. Kamga, S. Mendi and H. Imele, 2007. Activation of the Isctoperoxidise system as a method of preserving raw milk in areas without cooling facilities. Afr. J. Food Agric. Nutr. Dev., 7: 1-14.

$42889 j a$

Boots, J.W. and R. Floris, 2006. Lactoperoxidase: From catalytic mechanism to practical applications. Int. Dairy J., 16: 1272-1276.

$595412 j a$

FAO/WHO, 2005. Benefits and potential risks of the lactoperoxidase system of raw milk preservation. Report of an FAO/WHO Technical Meeting, November 28-December 2, 2005, FAO Headquarters, Rome, Italy, pp: 1-73.

$58223 a n$

C.J. and A. Chand, 2006. Capture of lactoferrin and lactoperoxidase from raw whole milk by cation exchange chromatography. Separation Purification Technol., 48, 143-149. 
iweja, L.W.T., M.J. Lewis and A.S. Grandison, 2008. Challenge testing the lactoperoxidase system against a range of bacteria using different activation agents. J. Dairy Sci., 91:

2566-2574

$433822 j a$

Hayashi, M., S. Naknukool, S. Hayakawa, M. Ogawa and A.B.A. Ni'matulah, 2012.

Enhancement of antimicrobial activity of a lactoperoxidase system by carrot extract and B-carotene. Food Chem., 130: 541-546.

$1174469 j a$

E., E.M. Buys and E.F. Donkin, 2004. Quality aspects of Gouda cheese made from goat milk preserved by the lactoperoxidase system. Int. Dairy J., 14: 581-589.

\section{$1181348 j a$}

E., E.M. Buys and E.F. Donkin, 2005. Significance of the lactoperoxidase system in the dairy industry and its potential applications: A review. Trends Food Sci.

Technol., 16: 137-154.

$571875 j a$

Singh, A.K., N. Singh, S. Sharma, K. Shin and M. Takase et al., 2009. Inhibition of lactoperoxidase by its own catalytic product: Crystal structure of the hypothiocyanateinhibited bovine lactoperoxidase at 2.3-A resolution. Biophys. J., 96: 646-654.

$568418 j a$

Touch, V.s S. Hayakawa, S. Yamada and S. Kaneko, 2004. Effects of a lactoperoxidasethiocyanate-hydrogen peroxide system on $<\mathrm{i}>$ Salmonella enteritidis $</ \mathrm{i}>$ in animal or vegetable foods. Int. J. Food Microbiol., 93: 175-183.

\section{$78030 j a$}

Zhou, Y. and L.T. Lim, 2009. Activation of lactoperoxidase system in milk by glucose oxidase immobilized in electrospun polylactide microfibers. J. Food Sci., 74: C170-C176.

$568445 j a$

Shahzaib 28-8-2013, \{Add by saira: 28-08-13 \}

Hypered by: Hina 28-8-13 
Fable 1. LPO activities of selution-obtained frem dilution- of $1 \mathrm{M}$ of $\mathrm{NaCl}$ in $\mathrm{PB}$ pH 7.0 threugh eaptured LPO frem bovine whey onte SP Sepharese Fast Flow in three-greups of fraction number. Data were obtained frem three replieations:

Figure 1. Immobilization efficiency (IE) of LPO on two types of resin. i.e. SP Sepharose BigBeads (SPBB) and SP Sepharose Fast Flow (SPFF). Two types of resin $(0.1-1.0 \mathrm{~g})$ was used to immobilized $1 \mathrm{ml}$ of LPO $(35 \mathrm{U} / \mathrm{ml})$. Flow rate has teen set to $1 \mathrm{ml} / \mathrm{min}$ using peristaltic pump. Values are means of three sets of experiments. Error bars represent standard errors of the mean.

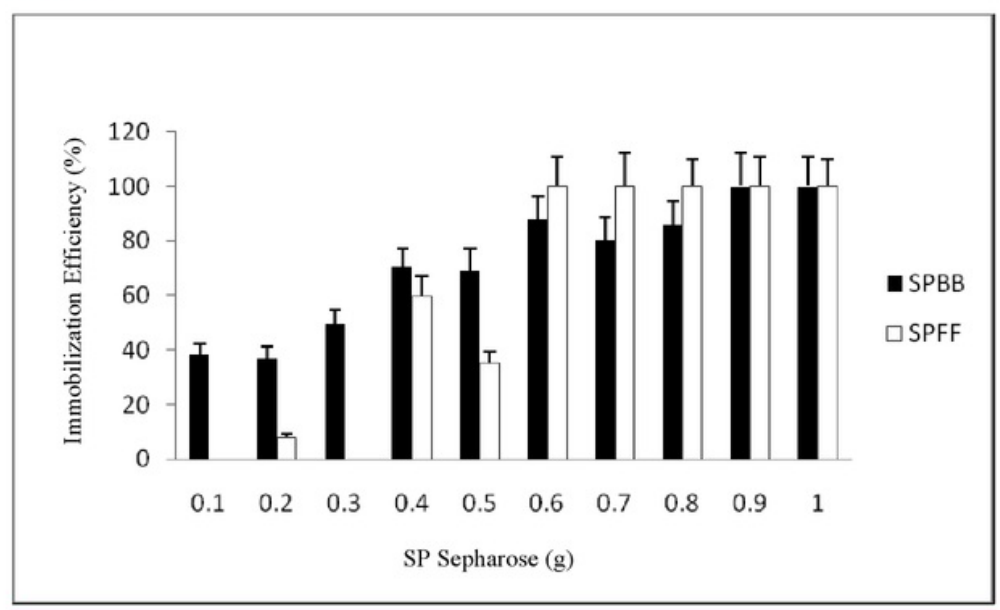

Figure 1. Immebilization effieieney of SPBB and SPFF using varieus weight.

Figure 2a. The percentage of remaining LPO aptivity attachedponto SP Sepharose Big Beads (SPBB) during 10 days of storage at $101 \mathrm{C}$ in $\sqrt{\text { arions }} \mathrm{St}$ tage folutions. This experiment used $1 \mathrm{~g}$ of SPB

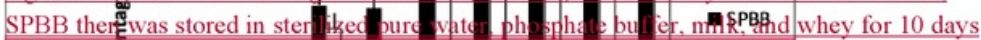

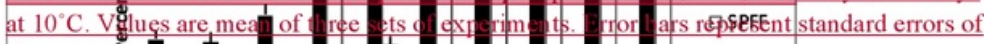
the mean

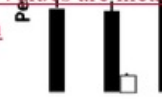

SP Sepharose

Figure 2b The percentage of remaining LPO activity attached onto SP Sepharose Fast Flow (SPFF) during 10 days of storage at $10^{\circ} \mathrm{C}$ in various storage solution. This
Commented [020]: Delete table 1 and explain its data in text, as it does not contain significant amount of data that needs to be presented in tabular form.

Commented [ANA21]: Table 1 has been deleted and the content has been explained in the text.

Commented [022]: Define all abbreviations used in figures in their respective captions.

Commented [023]: The given captions of your figures 1 and 2 have not been written properly. A figure should be self-explanatory and its caption plays a very important role in this regard. Provide such captions for all these figures in which all of their main parts have been properly explained.

Formatted: Indent: Left: 0", First line: 0"

Commented [024]: Define all abbreviations used in figures in their respective captions.

Commented [025]: The given captions of your figures 1 and 2 have not been written properly. A figure should be self-explanatory and its caption plays a very important role in this regard. Provide such captions for all these figures in which all of their main parts have been properly explained.

Formatted: Indent: Left: 0", First line: 0 "

Commented [FT26]: Assign an alphabet to each sub-part of Figure 2 and explain each figure part in figure caption by referring to its respective alphabet. A figure should be selfexplanatory and its caption plays a very important role in this regard. Provide such caption in which all main parts of this figure have been properly explained. All cited figures must be presented in the manuscript and all presented figures must be cited in the text at appropriate places along with their suitable explanation.

Commented [027]: In submitted manuscript Figure 2 has been presented but Author didn't cite this figure in text. Cite this figure in text at appropriate place with suitable explanation and make sure that all figures have been cited in text in consecutive numerical order. All cited figures must be presented in the manuscript and all presented figures must be cited in the text at appropriate places along with their suitable explanation.

Commented [ANA28]: Self explanatory has been added Commented [ANA29]: This figure has been presented in the article. 
experiment used $1 \mathrm{~g}$ of SPFF for immobilizing $1 \mathrm{ml}$ of LPO (35 U/ml). After immobilization. SPFF was stored in sterilized pure water, phe phate buffer, milk. and whey. Values are mean of three sets of experiments. Error bars represent standard errors of the mean

Figure 2a. The percentage of LPO activity attached ento SPBB during ten days of sterage in varieus-sterage-selutions

Figure $2 b$ The pereentage of $L P O$ aetivity attaehed onto SPFF during ten days of sterage in tarieus sterage selution:

Commented [FT30]: Assign an alphabet to each sub-part
of Figure 2 and explain each figure part in figure caption by referring to its respective alphabet. A figure should be selfexplanatory and its caption plays a very important role in this regard. Provide such caption in which all main parts of this figure have been properly explained. All cited figures must be presented in the manuscript and all presented figures must be cited in the text at appropriate places along with their suitable explanation.

Commented [031]: In submitted manuscript Figure 2 has been presented but Author didn't cite this figure in text. Cite this figure in text at appropriate place with suitable explanation and make sure order. All cited figures must be presented in the manuscript and all presented figures must be cited in the text at appropriate places along with their suitable explanation. Commented [ANA32]: Self explanatory has been added Commented [ANA33]: This figure has been presented in the article. 
RESISTANCE OF IMMOBILIZED LACTOPEROXIDASE ACTIVITY FROM BOVINE WHEY AGAINST STORAGE SOLUTIONS

ORIGINALITY REPORT

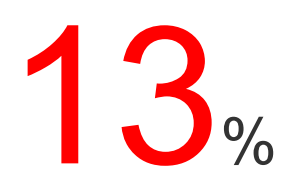

SIMILARITY INDEX
$\%$

INTERNET SOURCES
$13 \%$

PUBLICATIONS
$\%$

STUDENT PAPERS

MATCH ALL SOURCES (ONLY SELECTED SOURCE PRINTED)

$3 \%$

* Amir Golmohamadi, Matthew J. Morra, Inna Popova,

Caleb I. Nindo. "Optimizing the use of Sinapis alba seed meal extracts as a source of thiocyanate (SCN ) for the lactoperoxidase system", LWT - Food Science and Technology, 2016

Exclude quotes

Off

Exclude bibliography

Off
Exclude matches

\section{Off}

